\title{
El régimen laboral de los artesanos en Mérida, Venezuela: Sistemas y condiciones de trabajo (siglos XVI-XVII)
}

\section{Luis Alberto Ramírez Méndez \\ Universidad de Los Andes, Mérida- Venezuela luisramirez811@gmail.com}

Recibido: mayo de 2014

Aprobado: septiembre de 2014

Resumen: En la presente investigación se analizan las relaciones laborales en lo concerniente a las condiciones de trabajo, remuneración y capacitación del trabajo artesanal en Mérida durante los dos primeros siglos coloniales, las cuales se desarrollaron en el marco de cuatro sistemas de trabajo específicamente la encomienda, el concierto artesanal tanto de obra como de servicio, los asientos de aprendizaje y la esclavitud, los que posibilitaron el proceso de producción y obtener artesanías, lo cual reviste de especial importancia porque durante ese período se conformaron las bases de este tipo de relaciones laborales que aún se desarrollan en Latinoamérica. El trabajo muestra las formas de articulación del proceso productivo artesanal y los marcos de coerción legal, extralegal, y familiar a los que fueron sometidos los artesanos. La investigación se asienta sobre la información documental inédita y publicada que reposa en los archivos nacionales y extranjeros

Palabras claves: artesano, trabajo, concierto, servicio, producto, relaciones laborales, esclavitud, encomienda. 


\title{
The laboral regime of craftmanship in Mérida, Venezuela: the work systems and conditions (XVI-XVII centuries)
}

\begin{abstract}
In the present study examines labor relations as regards working conditions, remuneration and training of the craft in Merida during the first two colonial centuries, which was developed in the framework of four systems work specifically on the encomienda, the concert craft work both as service learning seats and the slavery, which enabled the craft production process for its products, which is of special importance because during this period the foundations of works relations that were formed yet developed in Latin America. The work shows the forms of articulation of the artisan production process and legal frameworks, extralegal coercion and relatives who underwent craftsmen. The research is based on the unpublished and published foreign documentary information rests at the national and foreing archives.
\end{abstract}

Key words: artisan, work, live, service, product, labor relations, slavery, encomienda.

\section{Introducción}

En América las culturas indígenas desarrollaron el proceso de producción artesanal alcanzando diversos niveles de sofisticación. En algunas regiones americanas, era una actividad extendida entre las civilizaciones precolombinas, cuyos miembros sabían tejer sus vestimentas, fundir oro, fabricar cerámica, tallar y grabar en piedra, hacer armaduras de algodón, trabajar artísticamente las plumas y edificar templos. ${ }^{1}$ Pero con la llegada de los peninsulares, el trabajo artesano creció ostensiblemente debido a la introducción de los aportes europeos, los que trajeron nuevos materiales, técnicas, instrumentos y propiciaron el surgimiento de novedosas necesidades.

Con la finalidad de satisfacer esos nuevos requerimientos, las autoridades coloniales permitieron e impulsaron el desarrollo de las artesanías y obrajes, cuando su producción no competiera con las manufacturas metropolitanas. Por esa ra-

1 Manuel Pérez Vila, “El artesanado, la formación de una clase media americana (1500-180o)”, en Boletín de la Academia Nacional de la Historia vol.LXIX, n. ${ }^{\circ}{ }^{274}$, Caracas, Academia Nacional de la Historia, 1986, p.327. 
zón para establecer obrajes y tejedurías se necesitó la autorización real. Esto sucedió en México donde los españoles construían grandes manufacturas ya en $1544,{ }^{2}$ al igual que en el Nuevo Reino de Granada, específicamente en Tunja y Duitama, donde se instituyeron talleres con la participación mixta de españoles e indios en $1599,{ }^{3}$ los que continuaron su funcionamiento durante el siglo XVII. Del mismo modo en Argentina y Paraguay, los jesuitas procedieron a formar y organizar artesanos guaraníes que construyeron y ornamentaron sus gigantescas iglesias misionales. ${ }^{4}$

Concretamente, en el espacio emeritense, ${ }^{5}$ el trabajo artesanal propiamente dicho, surgió íntimamente vinculado con la interacción ciudad-campo ${ }^{6}$ la que se conformó con el contacto indo hispánico y se consolidó a lo largo de los siglos coloniales, permitiendo por un lado que los trabajadores agrícolas aportaran las materias primas y semi-elaboradas necesarias en la confección de las artesanías y al mismo tiempo los artífices fabricaban las herramientas requeridas para el proceso de producción agrícola y pecuario. De esa forma, el artesano se convirtió en actor fundamental e indispensable en la construcción de las obras de infraestructura citadinas, en los pueblos indígenas y los núcleos de produccion rurales de los vecinos pudientes de la ciudad.

Para satisfacer las crecientes necesidades tanto de las edificaciones como de los procesos productivos particularmente agrícolas, fue de primordial importancia garantizar la presencia de operarios calificados esenciales en la recién creada realidad económica. Esa circunstancia determinó la decidida actuación de los privilegiados blancos de aquella sociedad, a los efectos de disponer de esa fuerza laboral que trabajaría en la fabricación de tan anhelados productos. En aras de aquel objetivo, introdujeron sistemas laborales, los que les posibilitaron administrar la coerción legal, económica y extraeconómica mediante los que compulsaron a los traba-

2 Richard Konetzke, América Latina la época colonial II, México, Ed. Siglo XXI, 1977, p.103.

3 Germán Colmenares, Historia económica y social de Colombia 1537-1719, Bogotá, Ed. la Carreta, 1978, pp.185-186.

4 Josefina Pla, "Los talleres misioneros, su organización y funcionamiento", en Revista de Historia Argentina n. ${ }^{\circ} 75-76$, Buenos Aires, 1973, pp.35-41.

5 La ciudad de Mérida y su jurisdicción perteneció al Nuevo Reino de Granada hasta que fue separada de la misma en 1777 y anexada a la Capitanía General de Venezuela por real cédula de Carlos III.

6 Luis Alberto Ramírez, La tierra prometida del sur del lago de Maracaibo y la villa y puerto de San Antonio de Gibraltar, t.I, Caracas, Ed. El Perro y la Rana, 2011, pp.177-228. 
jadores, fundamentándose en criterios legales, étnicos y atendiendo los modelos sociales de actuación importados de la península.

Aunque el trabajo artesanal ha sido estudiado con cierta profundidad, especialmente en lo referente a su tecnología, producción y comercialización, primordialmente en aquellas regiones hispanoamericanas en donde esa actividad alcanzó significativo desarrollo.7 Igualmente, ha suscitado especial interés en los investigadores cuando los artífices se han destacado en la realización de obras, las que han alcanzado una especial notoriedad debido a su elevado valor artístico y financiero, básicamente los pintores, escultores y orfebres, ${ }^{8}$ o cuando su trabajo ha sido primordial para la defensa militar. ${ }^{9}$ Además, otros estudiosos han explorado la conformación social del artesanado, asignándole un rol preponderante en la formación primigenia de las "clases medias" en Hispanoamérica y también como una actividad laboral propia de sectores sociales relegados en una sociedad profundamente estratificada, ${ }^{10}$ ubicando sus estudios mayoritariamente en la segunda mitad del

7 Josefina Pla, "Los talleres misioneros, su organización y funcionamiento", pp.9-53; Fernando Silva Santisteban, Los obrajes en el virreinato del Perú, Lima, Museo Nacional de Historia, 1964; Miriam Salas de Coloma, De los obrajes de Canaria y Chincheros a las comunidades indígenas de Vilcashuamán. Siglo XVI. Lima, Ed. Sesator, 1963; Xavier Ortiz de la Tabla, "El obraje colonial ecuatoriano. Aproximación a su estudio", en Revista de Indias n. ${ }^{\circ} 149-150$, Sevilla, EEHA/CSIC, 1977, pp.471-541; Robson Brines Tyrer, The demographic and Economic History of the Audiencia de Quito and the Textile Industry 16oo-180o, Ph. Discuss, University of California at Berkeley, 1976; Jean Pierre Tardieu, "Negros e indios en el obraje de San Ildefonso. Real Audiencia de Quito 16651666", en Revista de Indias vol.LXXII, n. ${ }^{\circ}$ 255, Sevilla, EEHA/CSIC, 2012, pp.527-550; Rafael Álvarez, "Artesanos y producción manufacturera en la Nueva Granada, la industria textil en la Provincia del Socorro, siglos XVIII y XIX”, en Procesos Históricos n. ${ }^{\circ}$ 10, Mérida, Universidad de los Andes, 2010, pp.1-40.

8 Carlos F. Duarte, "Historia y origen de varias obras atribuidas a Juan Pedro López", en Separata del Boletín Histórico n. ${ }^{\circ} 30$, Caracas, Fundación John Boulton, 1972; "El autor de la custodia preciosa de la catedral de Caracas", en Separata del Boletín Histórico . $^{\circ} 33$, Caracas, Fundación John Boulton, 1973; "Un portapaz del siglo XVI en la catedral de Caracas", en Separata del Boletín Histórico n. ${ }^{\circ}$ 41, Caracas, Fundación John Boulton, 1976; "Loza hecha en Venezuela durante la dominación española”, en Separata del Boletín Histórico n. ${ }^{\circ} 44$, Caracas, Fundación John Boulton, 1977; Los maestros fundidores en el período colonial en Venezuela, Caracas, Monte Ávila Eds., 1978; Ángel García Zambrano, El remodelado interior de la catedral de Puebla, Mérida, Universidad de Los Andes, 1984.

9 Sergio Paolo Solano, "Sistema de defensa, artesanado y sociedad en el Nuevo Reino de Granada. El caso de Cartagena de Indias. 1750-1810", en Memorias, vol.10, n. ${ }^{\circ} 19$, Barranquilla, Universidad del Norte, 2013, pp.2-139.

10 M. Pérez Vila, "El artesanado, la formación de una clase media americana (1500-180o)", pp.327-341; Jorge González Angulo, "Los gremios de artesanos y el régimen de castas", en Sonia Lombardo et al, (eds.), Organización de la producción y relaciones de trabajo en el siglo XIX en 
siglo XVIII, cuando el crecimiento demográfico citadino era apreciable al igual que el de este sector laboral.

Sin embargo, la artesanía es una proceso productivo que se desarrolla enmarcado en sistemas laborales, con relaciones particulares que son apenas reseñadas por algunos investigadores, ${ }^{11}$ pero cuyo estudio ha sido obviado y carece de un análisis sistemático especialmente en lo referido a las condiciones de trabajo, remuneración y capacitación, en particular durante los primeros siglos del dominio hispánico, lo cual reviste de especial importancia porque durante ese período se conformaron las bases de relaciones laborales ${ }^{12}$ de ese tipo, que aún se desarrollan en Latinoamérica.

De acuerdo con lo expuesto, la presente investigación se centra en el análisis de las relaciones laborales propias de la actividad artesanal en Mérida durante los siglos XVI y XVII, la cual se articuló y se desarrolló en el marco de cuatro sistemas de trabajo los que posibilitaron el proceso de producción artesanal para obtener sus productos, específicamente sobre la encomienda, el concierto artesanal tanto de obra como de servicio, los asientos de aprendizaje y la esclavitud, los que estuvieron firmemente cimentados sobre la estratificación social de aquella naciente colectividad.

La investigación se fundamenta sobre la revisión bibliográfica de la temática, particularmente en los estudios de Manuel Pérez Vila ${ }^{13}$ sobre el desempeño de los artesanos en el ámbito latinoamericano. En el caso de Mérida, sobre los trabajos

México, México, INAH, 1979, pp.148-159; María C. Navarrete, "Los artesanos negros en la sociedad cartagenera del siglo XVII", en Historia y Espacio n. ${ }^{\circ}{ }_{15}$, Cali, Universidad del Valle, 1994; María Duque Castro, "Nuevos ciudadanos entre el imperio español y la república colombiana" en Boletín Americanista vol.LX, n. ${ }^{\circ} 60$, Barcelona, Universidad de Barcelona, 2010, pp.165-186; Gina Herrera, Participación, presencia y prácticas de los artesanos afrocoloniales en Cartagena de Indias (1770 -1810). Bogotá, Universidad Javeriana, 2009; Hilda Farfán, "La artesanía en la provincia de Venezuela su importancia económica y social (1750-1850)", en Faces vol.6, n. ${ }^{\circ} 12$, Carabobo, Universidad de Carabobo, 1996, pp.108-133.

11 Elizet Payne Iglesias, "Maestros, oficiales y aprendices. La incipiente organización artesanal en la Cartago del siglo XVII", en Diálogos vol.1, n. ${ }^{\circ}$, San José de Costa Rica, Universidad de Costa Rica, 2000.

12 Un trabajo que aborda las relaciones laborales coloniales desde la perspectiva legal en J. J. Rivas Belandria, Antecedentes coloniales de nuestra legislación laboral, Mérida, Universidad de Los Andes, 1965.

13 M. Pérez Vila, "El artesanado, la formación de una clase media americana”, pp.327-341. 
de Tulio Febres Cordero, ${ }^{14}$ Luis Alberto Ramírez Méndez, ${ }^{15}$ Edda Samudio ${ }^{16}$ y esencialmente en la información recogida en la documentación original que se conserva en el Archivo General del Estado Mérida, fundamentalmente las escribanías españolas, en los fondos Protocolos y Mortuorias en cuyos manuscritos se conservan los testamentos, conciertos, cartas de dote, contratos que permiten indagar sobre las características del trabajo artesano, al igual que los que se resguardan en el Archivo General de Indias (Sevilla-España) y el Archivo General de la Nación (BogotáColombia).

\section{La encomienda}

En Mérida, al igual que en otras regiones de Hispanoamérica, los indígenas produjeron artesanías, entre ellas, adornos de plumas, cuentas de colores y tejían mantas de algodón, ${ }^{17}$ también, fabricaron ollas y vasijas de barro cocido y utilizaron algunos metales para elaborar sus ídolos ceremoniales. Esas sencillas actividades fueron rápidamente modificadas con la presencia del invasor español. Después del contacto indohispánico ${ }^{18}$ y la consiguiente implantación de numerosas costumbres, hábitos y técnicas en el suelo emeritense, los que ocasionaron notorios cambios en la realidad de las sierras nevadas.

Entre otras modificaciones, los peninsulares obligaron a los indígenas a abandonar sus costumbres ancestrales, por ello las sencillas ofrendas de hilo de

14 Tulio Febres Cordero, "Sobre el criollismo artes e industrias que fueron", en Tulio Febres Cordero, Mitos y tradiciones, Mérida, Universidad de los Andes, 1983, pp.169-170.

15 Luis Alberto Ramírez, La mano de obra artesana en Mérida 1623-1678. Ponencia presentada ante XXX Convención Anual de ASOVAC, Mérida, 1980; La artesanía colonial de Mérida 1623-1678, Mérida, (tesis) Universidad de Los Andes, 1980; “Tradición, familia y parentesco en el artesanado merideño de los siglos XVI y XVII", en Revista Montalbán n. ${ }^{\circ}$ 29, Caracas, Universidad Católica andrés Bello, 1996, pp.197-215; La artesanía colonial en Mérida (1558-1700), Caracas, Academia Nacional de la Historia, 2007; "Los maestros artesanos en Mérida (siglos XVI-XVII)", en Presente y Pasado vol.18, n. ${ }^{\circ}$ 36, Mérida, Universidad de los Andes, 2013, pp.28-52.

16 Edda Samudio, "La enseñanza de los oficios artesanales en Mérida", en El trabajo y los trabajadores en Mérida colonial. Fuentes para su estudio, San Cristóbal, Universidad Católica del Táchira, 1988, pp.267-312.

17 Pedro de Aguado, Recopilación historial de Venezuela, t.II, Caracas, Academia Nacional de la Historia, 1963, pp.401-402.

18 Lesley Bird Simpson, Los conquistadores y el indio americano, Barcelona, Eds. Península, 1970.

Dossier: Artesanos: formas de trabajo, sociabilidades, movilidad social y cultura política en Hispanoamérica, siglos XVI-XX 
algodón, cacao, chimó en los sagrados altares de sus dioses tutelares fueron consideradas como idolatras, ${ }^{19}$ terminantemente prohibidas y perseguidas. Asimismo, se obligó a los indígenas y esclavos africanos a vestirse a la usanza española, agruparse en núcleos urbanos ${ }^{20}$ al estilo europeo y laborar en las faenas que les asignaban los hispanos, especialmente en las haciendas y estancias rústicas, cuyo desarrollo demandó productos elaborados y semi-elaborados, vitales para el progreso de las actividades económicas, cotidianas, suntuarias y religiosas de la nueva realidad que se había creado.

De esa manera, la conformación de núcleos urbanos al estilo español en la cordillera merideña posibilitó el surgimiento del mercado con bienes de consumo de distintos tipos, en medio de una novedosa actividad comercial. Como resultado de ello, se conformó la demanda de telas para vestir la población blanca, indígena y esclava, de cueros para producir calzas, zapatos, sillas de montar, cofres y también fue necesaria la tala de árboles para la producción de maderas destinados a la fabricación de muebles, edificar las casas y los templos. ${ }^{21}$

Con la finalidad de satisfacer esas necesidades básicas e imprescindibles, los penínsulares contaron con una serie de factores endógenos en la cordillera merideña que les permitieron fomentar el proceso de producción artesanal a fin de disponer de aquellos bienes de consumo a bajo costo. Entre ellos, las fértiles terrazas intermontanas cuyos diversos pisos térmicos particularmente los fríos y templados posibilitaron la aclimatación del ganado ovino para la producción de lana destinada a los tejidos.22 Ademas, sus propicias condiciones climáticas y edáficas favorables

19 Véase al respecto los valiosos trabajos de Henry Kamen, La inquisición española, Madrid, Alianza Ed., 1974 y Julio Caro Baroja, Inquisición brujería y criptojudaismo, Barcelona, Ariel, 1974.

20 Sobre la implantación de los núcleos de población hispanós revísese para el caso neogranadino a G. Colmenares, Historia económica y social de Colombia. 1537-1719, pp. 7 y ss. En la Provincia de Venezuela ver a Federico Brito Figueroa, Historia económica y social de Venezuela, Caracas, Universidad Central de Venezuela, 1975. Sobre Mérida ver a Edda Samudio, Seventeenth Century Migration in the Venezuela Andes, Edited by David Robinson Cambridge Studies in Historical Geography, 1990, pp.215-312; Zoraida Santiago Lobo, Aspectos socioeconómicos de los esclavos negros en Mérida 1788-180o, Mérida, (tesis) Universidad de Los Andes, 1982.

21 L. A. Ramírez, La tierra prometida del sur del lago de Maracaibo y la villa y puerto de San Antonio de Gibraltar, t.II, pp.199-248.

22 En el testamento de Hernando Cerrada se declararon por bienes suyos 250 ovejas que estaban en los Timotes. Archivo General del Estado de Mérida (AGEM), Mortuorias t.I, Testamento del Capitán Hernando Cerrada. Trujillo 11 de enero de 1613, ff.1r.-14v. Igualmente entre los bienes de Juan Sánchez Osorio se hizo constar, “... Yten en Mocato un rebaño de mil ovejas...” AGEM, Protocolos t.XIII Testamento del capitán Juan Sánchez Osorio, Mérida 10 de julio de 1657, ff.109v.-114r. 
para el cultivo de algodón ${ }^{23}$ y diversas fibras textiles empleadas en la elaboración de tejidos. Entre tanto, otras zonas fueron apropiadas para la cría y ceba del ganado vacuno y la obtención del cuero, materia prima para las curtiembres, al igual que zonas boscosas con árboles cuyas maderas ${ }^{24}$ exóticas fueron taladas y empleadas en la fabricación de muebles, casas y templos. ${ }^{25}$ Del mismo modo, el rico surco del Chama proporcionó variados y abundantes recursos naturales, tales como canteras de arcillas utilizadas para la fabricación de tejas y lozas, ${ }^{26}$ los bloques de granito para la elaboración de los cantos labrados y sillerías. ${ }^{27}$ Lo expresado permitió que actividades artesanales se hicieran comunes en la provincia de las sierras nevadas.

Otro factor de importancia primordial, fue la existencia de una numerosa población aborigen sedentaria, que se constituyó en mano de obra necesaria para el proceso de producción artesanal, en algunas oportunidades sin remuneración y a bajo costo en otras. ${ }^{28}$

Para aprovechar esos recursos tanto naturales como humanos inmediatamente después de fundada Mérida, se procedió a la concesión de indios en enco-

23 En 1614, se avaluaron en los bienes de Hernando Cerrada, entre los cuales se contabilizaron 44 arrobas de algodón apreciadas en 7 pesos. AGEM, Mortuorias t.I, Testamento e Ynventario de Hernando Cerrada vecino de esta ciudad de Mérida, fechado a doze de enero de 1613. Inventario de los bienes de Chachopo. Chachopo, 8 de febrero de 1614, f.38r.

24 Existen referencias a la explotación de bosques madereros en las inmediaciones de Mérida, en ellas se hace mención a árboles de cedro, say-say y pino AGEM, Protocolos t.XIII,Obligación para entregar quince docenas de tablas, Mérida, 16 de julio de 1632, f.16r. Entre los bienes de Ana de Sulbaran Buenavida se avaluaron 219 tablas, 88 varas de cedro, 199 de say-say y las demás de pino. AGEM, Mortuorias t.I, Inventario de los bienes de Ana de Sulbaran Buenavida Mérida 18 de abril de 1639, f.175r.

25 Sobre la edificación de la iglesia mayor de Mérida existe el detallado trabajo de Ángel García Zambrano, "La Iglesia Mayor de Mérida", en Boletín de la Academia Nacional de la Historia vol.LXIX, n. ${ }^{\circ 276}$, Caracas, Academia Nacional de la Historia, 1985, pp.1079-1096.

26 AGEM, Protocolos t.IX, Carta de obligación para hacer teja y ladrillo, Mérida, 3 de abril de 1624, f.184r. AGEM, Protocolos t.X, Carta de concierto para hacer teja ladrillo y loza vidriada. Mérida, 22 de agosto de 1626, ff.139r.-140v. Pedro Gaviria Navarro declaró tener “... un texar camino del valle de los alisares ..." AGEM, Protocolos t.XXIII,Testamento de Pedro Gaviria Navarro, Mérida, 27 de mayo de 1657, ff.68v.-84v.

27 Investigaciones recientes han demostrado que “... los cantos destinados a servir de bases a las casas, conventos y templos provenían de las cabeceras de los ríos. Albarregas y Milla, son rocas metamórficas y areniscas de grano grueso muy meteorizadas, pertenecen a las formaciones Sierra Nevada y Mucujún del periodo precámbrico superior." Informe elaborado por Santosh K. Ghosh, Algunos Testimonios de la Arquitectura Colonial Merideña, Mérida, Museo de Arte Colonial y Facultad de Humanidades y Educación, 1981, p.11.

28 Antonio Mantilla, El régimen de la encomienda en Mérida, Mérida, (tesis) Universidad de Los Andes, 1979. 
mienda ${ }^{29}$ por Juan Rodríguez Suárez el fundador de la misma. ${ }^{30}$ De esa forma, la población aborigen fue constreñida a una nueva organización laboral de manera traumática y violenta, ya que la encomienda comportaba la asignación de los aborígenes a la autoridad de un español o encomendero a quien se le adjudicaba el derecho a beneficiarse del trabajo de los naturales en diversas actividades y exigirles el pago de prestaciones económicas. Por su parte, el encomendero se obligaba jurídicamente a proteger a los indios que le habían sido encomendados y a cuidar de su instrucción religiosa, con el auxilio de un cura doctrinero. Asimismo, el encomendero adquiría la obligación de prestar servicios militares cuando les fueran requeridos. ${ }^{31}$

En la ciudad de los picos nevados, al igual que en toda Hispanoamérica, la institucionalización de la encomienda representó el abuso de los encomenderos sobre los indígenas a quienes les exigieron la prestación de servicios personales, lo que motivó que fueran compelidos laboralmente, causándoles serios perjuicios debido a las excesivas faenas a las que fueron sometidos. Con la finalidad de evitar tales daños, la corona española prohibió expresamente la prestación de servicios personales, ${ }^{32}$ conmutándolos por el pago de tributo.

Con ese propósito, las autoridades coloniales procedieron a establecer la respectiva tasación para el pago de los tributos por los indígenas. Por ello en 1592, el juez Francisco de Berrío, al considerar que Mérida carecía de minas de oro y plata, que su actividad primordial era la agrícola, y atendiendo tanto a la densidad demográfica de la población aborigen, sus condiciones físicas, como las caracterís-

29 Sobre la encomienda existen valiosos aportes como, Francisco Jiménez, "Implantación de la Encomienda en la Provincia de Tabasco", en Anuario de Estudios Americanos vol.LVII, n. ${ }^{\circ}$, Sevilla, EEHA, 2000, pp.1338; Guther Khale, "La encomienda como institución militar en la América hispánica colonial", en Anuario Colombiano de Historia Social y de la Cultura n. ${ }^{\circ}$, Bogotá, Universidad Nacional, 1979, pp.5-16; Margarita González, "Bosquejo histórico de las formas del trabajo indígena", en Margarita González, Ensayos de historia Colombiana, Medellín, Ed. La Carreta, 1974, pp.9-63; Eduardo Arcila Farías, El régimen de la encomienda en Venezuela, Caracas, Universidad Central de Venezuela, 1967; Federico Brito Figueroa, Historia económica y social de Venezuela, Caracas, Universidad Central de Venezuela, 1975; G. Colmenares, Historia económica y social de Colombia; A. Mantilla, El régimen de la encomienda en Mérida; Reinaldo Rojas, El régimen de la encomienda en Barquisimeto colonial, Caracas, Academia Nacional de la Historia, 1992; Jorge Gamboa, "La encomienda y las sociedades indígenas en el Nuevo Reino de Granada. El caso de la provincia de Pamplona 1549-1650”, en Revista de Indias vol.LXIV, n. ${ }^{\circ 23}$, Sevilla, EEHA/CSIC, pp.749-770.

30 Probanza de Juan Rodríguez, Xuárez, Mérida, Consejo Municipal de Libertador. 425 años de la Historia de Mérida, 1983.

31 José María Ots Capdequí, El Estado español en las Indias, México, Fondo de Cultura Económica, 1975, p.16.

32 Recopilación de Leyes de Indias 1681, t.II, Lib.IV. Tit.XII, Ley I, Madrid, Cultura Hispánica, 1973, p.241. 
ticas morfológicas de la región, estableció la tasación de los tributos en especie. ${ }^{33} \mathrm{La}$ tasa de Berrío impuso a los indígenas la obligación de realizar diferentes actividades agrícolas y además hilar algodón y confeccionar lienzo, cuyo trabajo debería ser gratificado, con una manta de algodón, dos varas y media de lienzo, un sombrero de tierra y una ración de media fanega de maíz mensual. La tasación de Berrío se justificaba porque la producción de lienzo en Mérida y su jurisdicción, durante la segunda mitad del siglo XVI y primera mitad del XVII, tuvo una especial significación en su contexto económico. Ello se evidencia en la solicitud realizada por los vecinos de la ciudad, los que al carecer de suficiente plata amonedada pidieron que el lienzo circulara como moneda, acordándose que se darían cinco varas por un peso de oro de 20 quilates. ${ }^{34}$

Posteriormente en 1601, otro visitador Antonio Beltrán de Guevara nuevamente ordenó la supresión definitiva de los servicios personales y en su lugar estableció la concertación de los indios. A pesar de esa disposición, años más tarde en 1620, Alonso Vázquez de Cisneros pudo comprobar que los naturales seguían prestando servicios personales a sus encomenderos. Para evitar esa reiterada arbitrariedad, el visitador ordenó que los aborígenes pagaran sus tributos fijando la tasa en cinco pesos anuales y dos gallinas. Ese tributo podía ser cancelado en hilo de algodón por cuya razón se avaluó una libra de hilo en tres reales castellanos. De acuerdo a esa disposición se requería que cada indio útil y tributario en la jurisdicción de Mérida debería hilar 13,3 libras de hilo de algodón anual para pagar su tributo, lo cual debería ser multiplicado (por lo menos teóricamente) por 3.114 indios útiles y tributarios que el funcionario había empadronado en la jurisdicción de Mérida. ${ }^{35}$

La única excepción en el pago de tributos que hizo el visitador fue a los indígenas del pueblo de Chaquentá, pero les obligó a la cancelación de los estipendios del cura doctrinero, para cuya liquidación los encomenderos debían entregar 77

\footnotetext{
33 Edda Samudio, "La tasa para los indios de Mérida de 1593", en II Jornadas de Investigación Histórica, Caracas, Universidad Central de Venezuela, 1992, p.98.

34 Archivo General de Indias (AGI), Santa Fe, leg.536. t.10, Información solicitada por don Felipe el III a la Audiencia de Santa Fe, sobre la petición de los vecinos de Mérida para que el lienzo corra por moneda. San Lorenzo el Real, 16 de mayo de 1609. ff.99r.-100r.

35 El visitador Alonso Vázquez de Cisneros halló 3.114 indios útiles, con sus familias, todos sometidos a un duro trabajo personal incluyendo a las mujeres al arbitrio de sus encomenderos sin pagárseles por su trabajo, ni cumplir con las disposiciones regías dictadas en su beneficio.
}

Dossier: Artesanos: formas de trabajo, sociabilidades, movilidad social y cultura política en Hispanoamérica, siglos XVI-XX 
arrobas de algodón a los indígenas para ser hiladas, con cuyo producto se costeaba los 210 pesos anuales que constituían el salario del sacerdote.

De acuerdo con esas ordenanzas, los naturales se convirtieron en trabajadores artesanales especialmente en el trabajo textil. Así se desprende de los testimonios de la época en las que se manifestaba la contabilidad de los tributos pagados por los indígenas encomendados. Entre otros testimonios está el de Isabel González, tutora de su hijo Juan Sánchez Osorio a quien no entregó las debidas cuentas por la administración de los indígenas encomendados a éste, cuando él era menor, en los que se incluían los beneficios provenientes de las cosechas de maíz, las hilazas de lienzo de algodón y lino y otras granjerías. ${ }^{36}$ Igualmente, también se puede constatar en lo expuesto por Pedro Álvarez de Castrellón, encomendero de 34 indios del pueblo de la Sabana, ${ }^{37}$ quien se comprometió a entregar los tributos de éstos, en la labor tejer lienzo lo cual fue valorado en 3000 pesos. ${ }^{38}$ Adicionalmente a las tareas expresadas, tambien como parte del trabajo artesanal indígena se efectuaban las labores para confección de tintes vegetales, el tejido de las alfombras, los tapetes y cojines. ${ }^{39}$ Lo que es imposible de determinar es la cuantía de tributos pagados en textiles por los indígenas de la jurisdicción de los picos nevados y es preciso acotar que ya a mediados del siglo XVII, la tasación había perdido vigencia y los tributarios cancelaban sus démoras en otros productos agrícolas como papas, maíz, trigo, hortalizas y legumbres porque habían abandonado el trabajo artesanal y la producción de textiles.

36 AGEM, Protocolos t. XIII, Testamento de Isabel González, Mérida, 24 de septiembre de 1651, f. 4r.

37 Pueblo situado en las inmediaciones de Lagunillas, integrado por las parcialidades indígenas de Chiquimita, Capaz, Guachíes, Olleros, Potreros, Chuara, Estanques y Guaimaros, tenía 210 indios útiles y tributarios. Archivo General de la Nación-Colombia (AGNC), Sección Colonia, Visitas de Venezuela, t.II, Visita de Alonso Vázquez de Cisneros a Mérida. (Ordenanzas) Mérida, 17 de agosto de 1620 (exp.II) f.828v.

38 AGEM, Protocolos t.X, Carta de obligación de dote, Mérida, 17 de agosto de 1626, f.137r.

39 Sobre la elaboración de alfombras, tapetes y cojines, sus técnicas, tintes y otros aspectos interesantes revísese el trabajo de Carlos F. Duarte, Historia de la alfombra en Venezuela, Caracas, Ed. Arte, 1979. 


\section{El concierto artesanal}

El concierto artesanal ${ }^{40}$ se define como una modalidad de trabajo libre, contractual, asalariado y predominantemente urbano, originado en un contrato que obligaba a sus participantes a desarrollar una labor artesanal especifica o su enseñanza, por un periodo determinado, con una remuneración definida, autorizado ante una autoridad que daba fe de su cumplimiento. ${ }^{41}$ El concierto artesanal, se origina en la tradición gremial medieval en la que los artífices se organizaban siguiendo una serie de rígidas normas que regulaban el proceso de enseñanza aprendizaje, ascenso jerárquico y producción. ${ }^{42}$ En América, el concierto artesanal surge como respuesta a las disposiciones reales dictadas para evitar el abuso a que fueron sometidos los indígenas por sus encomenderos con la aplicación de los servicios personales. ${ }^{43}$ Con esa finalidad fueron emitidas una serie de regulaciones que establecieron taxativamente el trabajo libre asalariado indígena, al igual que de los mestizos, mulatos y negros libres y zambaigos. Esta modalidad de trabajo fue común en toda Hispanoamérica ${ }^{44}$ y particularmente en el Nuevo Reino de Granada desde inicios de la colonia. ${ }^{45}$

De igual manera, en Mérida fue empleado por personeros civiles y eclesiásticos para contratar artesanos a los efectos que realizaran obras de su oficio, como la

40 Sobre el concierto colonial se han realizado los siguientes trabajos, Marcelo Carmagnani, El salario minero en Chile colonial, Santiago de Chile, Universidad de Santiago de Chile, 1963. De igual manera, el trabajo de Álvaro Jara, "Importación de trabajadores indígenas en el siglo XVII", en Revista Chilena de Historia y Geografía n. ${ }^{\circ} 124$, Santiago de Chile, 1958, pp.192-207; "Fuentes para la Historia del Trabajo en el Reino de Chile III. Alquileres y ventas de Indios 1599-1620", en Apartado de la Academia Chilena de la Historia n. ${ }^{\circ}$ 58, Santiago de Chile, 1958, pp.102-135. En caso de Mérida, L. A. Ramírez, La mano de obra artesana en Mérida 1623-1678; La artesanía colonial de Mérida. 1623-1678, Mérida, (tesis) Universidad de Los Andes, 1980; Rosa La Marca Erazo y Ciria Lobo, El concierto en Mérida 1623-1690, Mérida, (tesis) Universidad de Los Andes, 1981.

41 Se establecieron las condiciones en que se desarrollarían las actividades laborales del artesano, taller, tienda, estancia o hacienda y las obligaciones del concertante con el artesano, se asentó que "... si faltare algún día de trabajo lo a de cumplir el dicho trabajo cumplido el año o descontando lo atrasado que montare dichas fallas...”. AGEM, Protocolos t.VIII, Concierto de trabajo entre Baltasar de los Reyes sillero y Bartolomé indio criollo, Mérida, 12 de junio de 1624, f.679v.

42 R. La Marca Erazo y C. Lobo, El concierto en Mérida 1623-1690, pp.27-36.

43 Recopilación de Leyes de Indias 1681, p.241.

44 G. Colmenares, Historia económica y social de Colombia 1537-1719, pp.144-146, y Testimonios para la formación del trabajo, Caracas, Instituto Nacional de Cooperación Educativa, 1972.

45 R. la Marca y C. Lobo, El concierto en Mérida 1623-1690, pp.27-36. 
construcción de casas, iglesias, decorar tabernáculos, pintar cuadros, fabricar puertas, llaves, candados y otros artículos, cuando se aplicó en esa forma se le denomina concierto de obra. También fue utilizado por los maestros artesanos cuando empleaban oficiales, obreros y ayudantes para trabajar en sus talleres a los efectos de cumplir con su labor en cuya modalidad se le denomina concierto de servicio artesanal

En la ciudad de los picos nevados, estuvo vigente desde el momento de la fundación de la misma (1558) y se usaba comúnmente, pero la regulación específica para la jurisdicción fue realizada en 1620 por Alonso Vázquez de Cisneros quien emitió las ordenanzas que normaban ese sistema laboral. En esas disposiciones reiteradamente se suprimió la prestación de servicios personales y se dictaminó que los indígenas debieran someterse al trabajo libre asalariado mediante el sistema de conciertos, ${ }^{46}$ lo que les proporcionaría una remuneración en metálico o en especie, ${ }^{47}$ la realción laboral tendría una duración temporal preestablecida. Con sus salarios, los indígenas podían pagar a sus encomenderos los tributos. ${ }^{48}$ De la misma forma, se reglamentó el trabajo en granjería (similar al destajo) para cuya realización los encomenderos suministrarían las materias primas trasladándolas hasta los pueblos de indígenas consignándoselas a los mismos, a los efectos de producir el hilo de algodón, lienzo, alfombras tapetes y cojines. ${ }^{49}$ Igualmente el funcionario creó el sistema de protección social al establecer que los concertantes deberían curar las enfermedades de sus concertados, exceptuándose cuando fueran contagiosas.

46 Guillermo Céspedes del Castillo, "La visita como Institución Indiana", en Anuario de Estudios Americanos Sevilla, t.III, Sevilla, EEHA, 1943, p.9.

47 AGNC, Visitas de Venezuela. t.II, Visita de Alonso Vázquez de Cisneros a Mérida (Ordenanzas), Mérida, 17 de agosto de 1620 (exp.II) f.828v.

48 En aquellos casos de incumplimiento de pago de tributos por los indígenas fueron reducidos a prisión, para abandonar los reclusorios les fue necesario presentar un fiador como lo realizó Alonso Hernández, oficial de zapatero a favor de Azencio de Carvajal, por los tributos atrasados que le debía a su encomendero Juan Carvaxal Mexía. AGEM, Protocolos t.XII, Carta de fianza, Mérida, 22 de febrero de 1631, f.68v. En otro testimonio se puede apreciar el grado de compulsión a que fue sometida la población aborigen tributaria, como sucedió con Leonardo indio de la encomienda de Dionisio Izarra, encarcelado, por 20 patacones que debía de sus demoras, por lo cual Joseph de Roxas, prestó una fianza para garantizar el deudor “...fuese suelto de la prisión por tiempo de los veinte días de pascua del espíritu santo... comprometiéndose el fiador a que una vez cumplido el plazo volvería a las rejas de la cárcel pública a entregar a Leonardo indio...”, en su defecto pagaría los veinte pesos adeudados. AGEM, Protocolos t.XXVIII, Carta de fianza, Mérida, 9 de junio de 1669, f.23v.

49 El visitador Alonso Vázquez de Cisneros estableció “...que se les pague a cada uno de ellos catorce pesos y el sustento necesario que fuere menester..." AGNC, Visitas de Venezuela t.II, Visita de Alonso Vázquez de Cisneros a Mérida (Ordenanzas), Mérida, 17 de agosto de 1620 (exp. II) f.829v. 
La libertad de contratación que el concierto proporcionaba en cierta medida permitió a los trabajadores de las diferentes etnias escoger el oficio, lugar y patronos para laborar, estipular la duración del periodo de trabajo y percibir remuneración, lo cual estuvo garantizado por marcos de coerción legales. En tanto que a los propietarios de haciendas y estancias se les posibilitó disponer de personal calificado con el objeto de desarrollar los procesos técnicos complementarios en el proceso de producción agrícola. ${ }^{50}$

\subsection{Salario y duración de los conciertos artesanales}

La cancelación de salarios ${ }^{51}$ a los artesanos emeritenses tuvo tres modalidades: en metálico, mixto y en especie. El salario en metálico se expresaba taxativamente en pesos, mientras el mixto incluyó aportes en metálico, la alimentación, vivienda, herramientas, animales de carga, engorde y ceba y en especie solo se remuneró con la enseñanza de los oficios, la alimentación, asistencia médica, religiosa; las herramientas y el uniforme del oficio.

La cancelación del salario en metálico a los artesanos emeritenses estuvo directamente vinculado con las posibilidades que ofrecía el sistema monetario colonial merideño, el cual estubo severamente limitado por la carencia de metales preciosos, en especial de plata amonedada, por cuya razón se recurrió a mecanismos sustitutivos de ésta, específicamente durante el siglo XVI y primeras décadas del XVII. A consecuencia de esa eventualidad, en la remuneración del trabajo artesano esencialmente en la contratación de obras, se debió recurrir a otros signos de intercambio que circulaban legalmente en Mérida. Por ese motivo, se hizo expreso señalamiento en el pago de los salarios por el trabajo artesano en pesos de lienzo, Después de la tercera década del siglo XvII, evidentemente el ingreso de plata amonedada desde Veracruz, la que se cancelaba por la exportación de cacao a ese puerto aumentó la circulación de la misma, porque el sueldo para las obras artesanales se paga en metálico (véase tabla 1).

50 El Gobernador Juan Pacheco y Maldonado concertó a Cristóbal de Xaramillo para la enseñanza del oficio de herrero a dos esclavos suyos. AGEM, Protocolos t.XII, Concierto para enseñanza de esclavos, Mérida, 18 de junio de 1632, f.125r.

51 El salario ha sido definido como "el ingreso de los no poseyentes activos", y se consideran a los "no poseyentes activos aquellos que no son propietarios de los medios de producción y que por su trabajo reciben una remuneración”. Pierre Vilar, Iniciación al vocabulario histórico, Barcelona, Grijalbo, 1980, p.139.

Dossier: Artesanos: formas de trabajo, sociabilidades, movilidad social y cultura política en Hispanoamérica, siglos XVI-XX 
Tabla 1: Conciertos para obras y su salario en Mérida, 1558-1700

\begin{tabular}{|l|l|l|l|l|c||}
\hline \hline Años & \multicolumn{1}{|c|}{ Concertante } & \multicolumn{1}{|c|}{ Concertado } & \multicolumn{1}{|c|}{ Oficio } & \multicolumn{1}{|c|}{ Obras } & $\begin{array}{c}\text { Salario } \\
\text { (\$) }\end{array}$ \\
\hline 1581 & H. Cerrada & Bartolomé Bravo & Carpintero & Un molino & 80 \\
\hline 1581 & F. Trejo & Álvaro Martín & Carpintero & Un molino & 85 \\
\hline 1592 & N. Fernández P. & B. Ximenez & Carpintero & Iglesia mayor & 700 \\
\hline 1595 & Agustinos & Juan de Milla & Albañil & Iglesia de S.A. & 160 \\
\hline 1606 & Luis Morales & Cristóbal Pérez & & El hospital & 255 \\
\hline 1612 & B. Maldonado & Francisco López & Escultor & Una imagen & 30 \\
\hline 1614 & J. García de la P. & Andrés Carrillo & Carpintero & Una reja de i. & - \\
\hline 1625 & Lorenzo Cerrada & Hernandode Rojas & carpintero & Una casa & 92 \\
\hline 1625 & Lorenzo Cerrada & Pablo Meneses & tejero & 6ooo tejas & 30 \\
\hline 1638 & Diego Prieto D. & Gaspar Fernández & carpintero & C de Sta. Clara & 200 \\
\hline 1638 & Antonio Arias M. & Diego Mendoza & carpintero & Una casa & 190 \\
\hline 1652 & Juan F. de Arrue & Juan T de Lorca & albañil & Una casa & 130 \\
\hline 1653 & Rector de la C de J & Mateo Leal & carpintero & Iglesia de la C. & - \\
\hline
\end{tabular}

Fuente: AGEM, Protocolos ts. I-XL y Mortuorias t.I-X

A diferencia del concierto de obra; en el de servicio artesanal, hasta 1630, prevalece la modalidad de pago en salario mixto, en la que aparte de la remuneración en metálitco también se contemplaron otras formas de retribución como la entrega de herramientas y animales de carga, engorde y ceba. ${ }^{52}$ Pero a partir de esa fecha y hasta 1660 se mantiene solo en metálico y después de esa década se retorna a la modalidad mixta. Los lapsos para el pago del salario se fijaron semestralmente, específicamente el día de San Juan (24 de junio) y el de navidad (24 de diciembre) o bien, cuatrimestrales. ${ }^{53}$ A partir de la sexta década del siglo XVII, los conciertos de servicio artesanal no establecen duración temporal definida y la cancelación del salario se hace diaria o mensual (véase tabla 2).

52 En un concierto entre Hernando Cerrada y Bartolomé, Bravo, carpintero y Francisco de Castro, para hacer un molino, éstos percibirían por su trabajo “... ochenta pesos de oro, la mitad en lienzo curado a cinco varas el pesos y la otra mitad en caballos valorados por dos personas que los entienda ...". AGEM, Protocolos t.I, Carta de concierto, Mérida, 6 de enero de 1591, f.140.

53 AGEM, Protocolos t.XII, Concierto de servicio, Mérida, 20 de mayo de 1635, f.152v. 
Tabla 2: Conciertos de servicio artesanal en Merida, 1558-1700

\begin{tabular}{|l|l|l|l|l|c|c|c|}
\hline Fecha & \multicolumn{1}{|c|}{ Concertante } & \multicolumn{1}{|c|}{ Concertado } & \multicolumn{1}{c|}{ Oficio } & \multicolumn{1}{|c|}{ Servicio } & $\begin{array}{c}\text { Sal } \\
\text { (\$) }\end{array}$ & esp & Años \\
\hline 1596 & H. Cáceres & A. Inserna & Curtidor & En su oficio & 44 & x & 1 \\
\hline 1610 & J. de S. Martín & Andrés & Sastre & En su oficio & 48 & $\mathrm{x}$ & 1 \\
\hline 1624 & B. de L. Reyes & Bartolomé & sillero & En su oficio & 60 & - & 1 \\
\hline 1627 & J. Pacheco y M. & A. Vázquez & zapatero & enseñanza & 30 & - & 2 \\
\hline 1627 & D. Varela & P. Fernández & herrero & enseñanza & 75 & - & 3 \\
\hline 1627 & M. Iragui & Juan Indio & & En fragua & 42 & - & 1 \\
\hline 1632 & J. Pacheco M. & C. Xaramillo & herrero & enseñanza & & $\mathrm{x}$ & 3 \\
\hline 1632 & A. de Luna & Aszencio & zapatero & En su oficio & 30 & - & 1 \\
\hline 1658 & E. de Aguado & N. Montoya & sillero & En su oficio & 70 & - & 1 \\
\hline 1662 & J. Gutiérrez & F. Vázquez & herrero & En su oficio & $*$ & $\mathrm{x}$ & 1 \\
\hline 1163 & E. de Aguado & E. Sánchez & sillero & En su oficio & $* *$ & $\mathrm{x}$ & - \\
\hline
\end{tabular}

Fuente: AGEM, Protocolos ts. I-XL y Mortuorias t.I-X

Leyenda: $\mathrm{x}$ : pago de salario en especie.

-: sin pago de salario en especie.

$*: 2$ reales diarios.

$* * 4$ patacones mensuales.

En cuanto a la duración de los conciertos se pueden dividir en tres categorías. Los conciertos de obra artesanal, tienen permanencia variable, lo cual está directamente relacionado con el sistema de financiamiento para la realización de las obras. ${ }^{54}$ La carencia del capital o bien su presencia permitía que el tiempo de duración para ejecutar la obra fuese corto o largo, mientras los conciertos para servicio artesanal fueron mayoritariamente de un año, algunos de dos y en otros de tres (véase tabla 2 y gráfico 1).

54 AGEM, Protocolos t.XII, Concierto de servicio, Mérida, 20 de mayo de 1635, f.152v. 


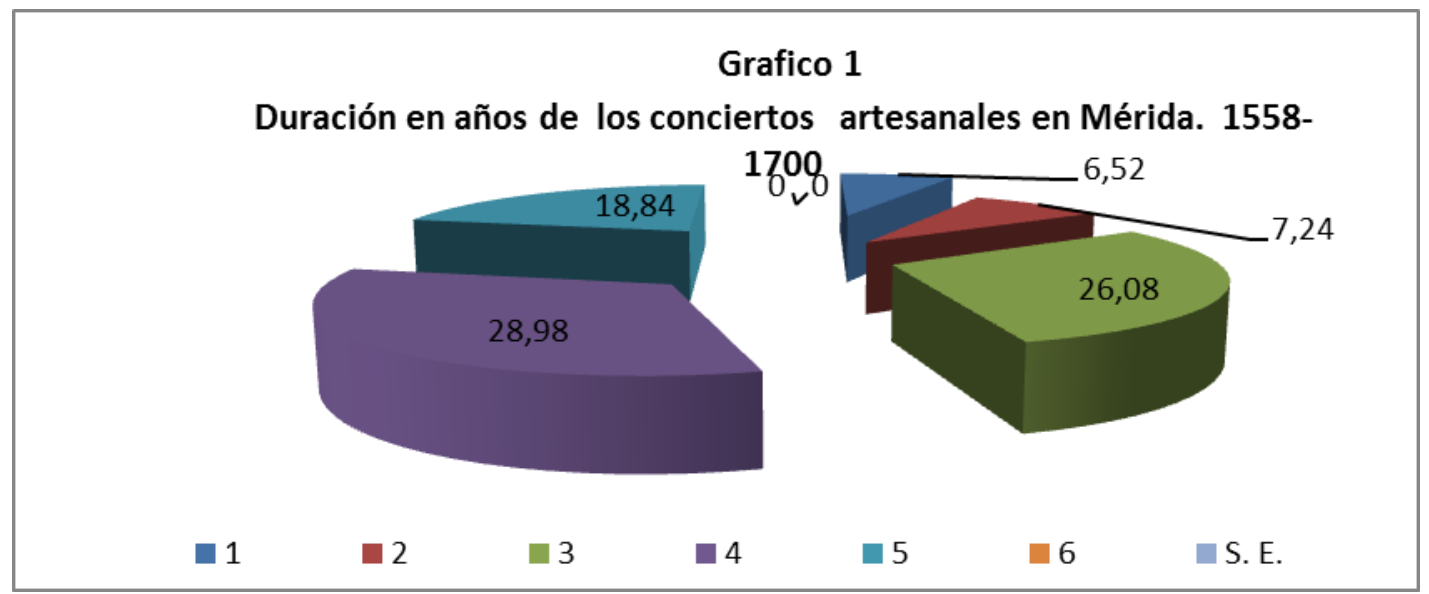

Fuente: AGEM, Protocolos ts. I-XL y Mortuorias t.I-X.

\section{Los asientos de aprendizaje}

La necesidad de satisfacer la creciente demanda de bienes de consumo en Hispanoamérica, generada por la incapacidad de la metrópoli de proveerla, determinó la necesidad de introducir talleres para la producción de esos productos. Como resultado de ello, la sociedad iberoamericana vio surgir en su seno desde mediados del siglo XVI y fortalecerse en las centurias posteriores los talleres y tiendas artesanales y manufactureras en los cuales se procedió a la enseñanza a los naturales para fabricar sus productos. Aquel proceso de transferencia de tecnología artesanal se inició con la emigración de artífices europeos, que trajeron consigo las técnicas y herramientas propias de cada oficio. En ese sentido Manuel Pérez Vila afirma que el ejercicio de los operarios representó un factor de cohesión, similar al que en la religión ejercieron los sacerdotes. De esa forma los artesanos se concentraron en las grandes capitales virreinales, o en las sedes de las audiencias, donde residían la mayoría de sus potenciales clientes, pero su presencia fue común en todas las ciudades de Hispanoamérica. 55

De ese modo, el aprendizaje de los oficios artesanales ${ }^{56}$ se adquirió en los talleres y tiendas de los maestros con quienes se asentaban los aprendices. Mediante, ese instrumento jurídico, cuya primordial finalidad fue la proporcionar a los jóve-

55 M. Pérez Vila, "El artesanado, la formación de una clase media americana (1500-1800)", p.328.

56 E. Samudio, “La enseñanza de los oficios artesanales en Mérida colonial”, pp.267-279. 
nes la capacitación necesaria para el ejercicio de un oficio artesanal. El proceso de enseñanza-aprendizaje se cumplió en mediante un ciclo en el cual el aprendiz adelantó en el conocimiento teórico práctico hasta obtener la calificación necesaria que lo acreditaba como oficial y finalmente se le ascendía a maestro. Ese proceso educativo se cumplió en dos fases en la primera el maestro le aportaba sus nociones y la orientación necesaria para enseñarle las bases teóricas del oficio, en la segunda el principiante desarrollaba sus destrezas y habilidades en la práctica cotidiana bajo la supervisión directa de su maestro.

Aquélla enseñanza se extendió mas allá de impartir los conocimientos del operario del oficio, también el maestro asumió la tutoría del aprendiz, quien en su convivencia diaria se instruyó en los principios éticos, morales y religiosos, los que su preceptor tenía la obligación de inculcarle, así como la disciplina y el respeto al orden establecido. ${ }^{57}$ Por su parte, el educando estaba comprometido a atender diligentemente las enseñanzas de su mentor y a "no cometer falta alguna", durante un periodo previamente estipulado. ${ }^{58}$

Las obligaciones del instructor también involucraban la provisión de la alimentación al principiante, su asistencia médica, sólo excluida cuando las enfermedades fueran contagiosas y al finalizar el periodo de instrucción, debería entregar un vestido entero, una especie de uniforme y las herramientas del oficio al aprendiz. De esa forma, el proceso de enseñanza se desarrollaba en un ambiente donde los maestros y estudiantes laboraban en estrecho contacto, los últimos ayudaban y reproducían los modelos de los primeros, mientras las innovaciones propuestas por los más aventajados eran certificadas y copiadas por los otros. ${ }^{59}$ Una vez concluido el proceso de educación, los aprendices aprobados ascendían al rango de oficiales, para lo cual debieron cumplir con el requisito de legal de prestar fianzas para asegurar el fiel cumplimiento de su oficio mediante el cual entregarían fielmente sus

57 Se establecían las condiciones en las cuales se desempeñaría el artesano, en la tienda, taller, estancia, o hacienda y las obligaciones del concertante con el artesano. AGEM, Protocolos t.XXV, Carta de concierto entre Juan Sánchez Osorio con Estaban Aguado sillero para que le sirva en sus haciendas, Mérida, 20 de noviembre de 1663, f.265.

58 Se establecía que “... si fallare algún día de trabajo los ha de cumplir el dicho trabajo cumplido el año o descontando lo atrasado que montare las dichas fallas..." AGEM, Protocolos t.VIII, Concierto de trabajo entre Baltasar de los Reyes Sillero y Bartolomé, Indio criollo, Mérida, 12 de junio de 1624, f.679v.

59 Carlos F. Duarte, Muebles venezolanos. Siglos XVI, XVII y XVII, Caracas, Grupo Cuatro Editor, 1966, p.20. 
obras, darían buena cuenta del desempeñó en su labor y garantizaban el trabajo del novel oficial. 60

La formación artesanal fue protegida y auspiciada en aquella sociedad, donde las oportunidades para obtener educación eran limitadas y especialmente reducidas a los estratos privilegiados. Por esas razones los sectores menos pudientes expresaron su decidida aceptación para que sus miembros adquirieran la formación inherente a los oficios y obtuvieran la capacitación necesaria. ${ }^{61}$ En ese mismo sentido, el cabildo emeritense, también preocupado por resolver la problemática de la orfandad procedió a asentar los huérfanos como aprendices con diferentes maestros, a los fines de proporcionarles una formación intelectual, moral, técnica y religiosa a la infancia desamparada de la ciudad ${ }^{62}$ y evitar que estos estuvieran desamparados y vagando. ${ }^{63}$ Con ese propósito, el ayuntamiento instruyó a los, maestros u oficiales artesanos que tuviesen tiendas o talleres, que deberían asentar a los niños, jóvenes o mozos con la finalidad de enseñarles sus oficios ${ }^{64}$ y también evidente-

60 En 1657 Juan Félix de Arrue y Roxas otorgó fianza en favor de Juan Pérez Dávila, oficial de sastre, en la tal forma “... que Juan Pérez Dávila, dar en pago de todas sus obras que se le dieran a hazer por lo que los terceros que se lo dieren en concierto de palabra lo cumpla todo y haciendo negocio y caso ajeno suyo propio en todo los que le concierne...". AGEM, Protocolos t.XXIII, Carta de fianza, Mérida, 18 de agosto de 1657, f.98v. En 1663, Lope de La Cruz, vecino de Mérida, sé constituyo en fiador de Domingo Hernández Martín, indio maestro de cerero, “... en tal manera que el suso dicho dar buena quenta de la será que labore y la entregar a los dueños que se la dieren a satisfacción y sin contención ni engaño y cumplir con la obligación que corre con el dicho oficio..." AGEM, Protocolos t.XXV, Carta de fianza, Mérida, 16 de noviembre de 1663, f.260v.

61 En una ocasión se asentó por aprendiz a un mozo, llamado Juan Rodríguez, criado del Alférez Antonio Arias Maldonado, quién le había enseñado a leer y escribir, y cual inusualmente firmó su Carta de asiento con la aprobación del mencionado alférez. AGEM, Protocolos t.XXVII, Asiento de aprendiz, Mérida, 20 de junio de 1668 , f.58r-v.

62 En cuanto a las órdenes del cabildo se pueden señalar el asiento de aprendiz entre Francisco Rivas, maestro de sastre y Lucas Gordillo, a quien Nicolás Rangel de Cuéllar Alcalde ordinario mandó por auto se concertara. AGEM, Protocolos t.XXXI, Asiento de aprendiz. Mérida, 10 de marzo de 1678. En 1663, Cristóbal Joseph de Nava y Salas, alcalde ordinario de la ciudad, puso por aprendiz con Miguel de Rojas, maestro de batihoja de plata y oro a Juan de Aranguren, huérfano, en conformidad con lo mandado por el mismo. AGEM, Protocolos t.XXXV, Asiento de aprendiz, Mérida, 20 de noviembre de 1663, f.265v.

63 En un asiento de aprendizaje de sastrería entre Pedro Ponce de San Martín, maestro del oficio y Fabián Pérez, se expresó, que éste deseaba aprender el oficio para “... tener con que vivir y no andar bagando..." AGEM, Protocolos t.XXV, Asiento de aprendiz, Mérida, 5 de septiembre de 1662, f.101v.

64 Al respecto se pueden citar numerosos asientos de aprendizaje, entre ellos el de Gregorio Gaviria, maestro de curtidor, y Juan de Aranguren, en el cual se expresa que el maestro "está administrando una tenería”. AGEM, Protocolos t.XXVI, Asiento de aprendiz, Mérida, 9 de julio de 1664, f.96r. De igual forma se señala en el asiento de aprendiz de zapatero entre el oficial Domingo de Trujillo con Félix Santiago, en el cual se hace constar que el oficial tiene tienda pública en la plaza de la ciudad. AGEM, Protocolos t.XXI, Asiento de aprendiz, Mérida, 25 de abril de 1671, f.55r. 
mente existió la preocupación de los padres de los aprendices, quienes manifestaron explícitamente estar de acuerdo con que sus hijos y criados, adquirieran aquella formación y consiguieran la capacitación necesaria para poder sustentarse con su trabajo. ${ }^{65}$

La intencionalidad de aprender el oficio, también estuvo determinada por la propiedad de los medios de producción, la posesión de tenerías y fraguas motivó que sus propietarios inclinasen a sus hijos en la instrucción de ese oficio. ${ }^{66}$ Esto, explica, la existencia de padres e hijos que desempeñaron los mismos oficios o similares. Un caso de estos fue el de Juan Aranguren, niño, hijo de Magdalena de Mora, propietaria de una tenería, quien carecía de un operario que efectuara el proceso de curtiembre, por ello, manifestó su deseo que el infante aprendiera el oficio de curtidor y surrador. ${ }^{67}$

Eventualmente, ocurrió que por diversas causas, entre las que presumiblemente estuviera la falta de interés por el aprendiz en desarrollar su labor u otra se ocasionó la ruptura del asiento de aprendizaje. ${ }^{68}$ En esos casos, los novicios habían

65 Entre otros casos, se pueden mencionar los siguientes. En 1624, Francisco Gutiérrez, indio, expresó que tenía un hijo que “... quiere poner por aprendiz y lo asienta con Juan Rodríguez, vecino de esta ciudad oficial de herrero para que le enseñé el oficio...” AGEM, Protocolos t.IX, Asiento de aprendiz. Mérida, 28 de agosto de 1624, f.47r. En 1625, Juana, india, ladina y partera de esta ciudad asentó por aprendiz a un hijo suyo con Juan Gómez de Orozco para que le enseñe el oficio de zapatero. AGEM, Protocolos t.x, Asiento de aprendiz, Mérida, 14 de agosto de 1625, f.7or. En 1626, Susana, india ladina de Mérida, puso y asentó por aprendiz a su hijo llamado Diego con Baltazar de los Reyes sillero para que le enseñara el oficio. AGEM, Protocolos t.XI, Asiento de aprendiz, Mérida, 15 de septiembre de 1626, ff.107r-v. De igual forma en 1665, fue asentado Gregorio Ravelo, con Gregorio García maestro de curtidor bajo expresa voluntad de su madre Isabel Pulida. AGEM, Protocolos t.XXI, Asiento de aprendiz, Mérida, 5 de mayo de 1665, f.176v.

66 Esto se observa en Juan Santiago el viejo y Juan Santiago el mozo, ambos maestros de surradores, de igual forma en Juan Cordero de Trejo y sus sobrinos Juan Trejo y Lorenzo Vazán, plateros; Antón Corzo y Juan Corzo, Gonzalo García de la Parra y Juan García de la Parra, herreros Pedro Fernández Oxeda, el viejo y Pedro Fernández Oxeda el mozo. Luis A. Ramírez, Mérida, mestiza y artesana (en preparación).

67 En el documento se expresa, que Juan de Aranguren “... se ha inclinado siempre al oficio de curtidor y por que la tenerla que hay en esta ciudad del zitio casos hoyos y herramientas... y que perteneze a Magdalena de Mora, su madre, y le a de suceder precisa maestro en ella... y por las razones que lleva referidas quiere concertarse por aprendiz..." AGEM, Protocolos t.XXVI, Asiento de aprendiz, Mérida, 9 de julio de 1664, f.96r.

68 En 1627, Andrés de Luna, tomó por aprendiz de zapatero a Pedro Criollo, por tres años siguientes, sin embargo en 1629, dos años después el asiento de aprendizaje fue disuelto por ambas partes, 
obtenido ciertos conocimientos sobre el oficio y se concertaban nuevamente recibiendo salario en metálico, manteniendo su rango de aprendices, ${ }^{69}$ ocasionalmente, se conmutaba la entrega del respectivo uniforme y herramientas por el pago en metálico. ${ }^{70}$

Los asientos de aprendizaje tienen una mayor duración, ello se debió a la necesidad de mayor tiempo destinado a la enseñanza de un oficio. Por ello, el 26,08\% de los asientos de aprendizaje se extendieron a 3 años y el 28,98\% fueron de 4 años (véase gráfico 1) Ello, indica que el proceso de enseñanza aprendizaje fue cumplido mayoritariamente entre tres o cuatro años. A pesar de lo indicado, se puede notar que hubo notables diferencias entre la duración de los asientos de aprendizaje en los distintos oficios, en algunos, tuvo relación con la edad del concertado, cuando eran niños, mozos, muchachos, o mancebos. En otras ocasiones se mencionó que ya tenían rudimentos sobre el oficio y por esa razón el concierto tuvo menor duración.

El ciclo del proceso de enseñanza-aprendizaje puede ser visualizado a través del zapatero Azencio, un indio de la encomienda de Juan Carvajal Mexía, quien en 1627 fue asentado como aprendiz, con Andrés Álvarez, maestro de aquel oficio por el gobernador Juan Pacheco y Maldonado durante tres años, ${ }^{71}$ pero alguna causa desconocida impidió que el anterior concierto concluyera como se había establecido, pues ocho meses después el indígena fue asentado nuevamente con Juan Pascual, para que le instruyera el mismo oficio durante un año.72

como consta en la nota marginal del documento. AGEM, Protocolos t.IX, Asiento de aprendiz, Mérida, 12 de agosto de 1627. (Nota marginal de fecha Mérida, 3 de abril de 1629), f.37or.

69 En 1625, Juana, india partera de Mérida, asentó a su hijo, Marcos, con Juan Gómez de Orozco, para que le terminara de enseñar el oficio de zapatero, puesto que Marcos, era costurero. Juan Gómez de Orozco se comprometía a pagar a Marcos 24 pesos de plata en un año de concierto. AGEM, Protocolos t.X, Asiento de Aprendiz, Mérida, 14 de agosto de 1625, f.3or.

70 En 1643, Gaspar indio de San Cristóbal, se asentó por aprendiz de sillero con Juan Montoya, por cuatro años, comprometiéndose Juan Montoya, sólo a darle buen tratamiento, curarle sus enfermedades, darle bula de la santa cruzada, doctrina cristiana y pagarle al concluir el asiento 30 pesos de plata. Se omite expresamente el compromiso de la alimentación, el vestido, y las herramientas del oficio. AGEM, Protocolos t.XII, Carta de asiento de aprendiz, Mérida, 22 de septiembre de 1623, f.236v.

71 AGEM, Protocolos t.x, Carta de asiento de aprendiz. Mérida, 20 de diciembre de 1627, f.196r.

72 AGEM, Protocolos t.XI, Carta de asiento de aprendiz, Mérida, 20 de diciembre de 1627, f.249v. 
Posteriormente, el 9 de abril de 1631, Alonso Hernández, también oficial de zapatero, se comprometió pagar anualmente a Juan Carvajal Mexía encomendero del aborigen, dos pesos de plata por sus demoras, correspondientes al tiempo que el operario tenía vencidas y por aquellas que corriesen en adelante. ${ }^{73}$ Cuatro años más tarde en 1635, Azencio, como oficial se comprometió a trabajar con Andrés de Luna, en su tienda, por un año. Allí, el patrono le proveería el cordobán, las suelas y el calzado cortado, mientras el trabajador se obligó a entregar dos pares de zapatos diarios y tres en vísperas de fiestas, con la remuneración de cincuenta reales de a ocho. Es interesante resaltar, que a partir de esa fecha el artesano se apellidó Carvajal al igual que su encomendero. ${ }^{74}$ Años más tarde, en 1652, Francisco Martín Gerena, sastre, vecino de Mérida, declaró que el zapatero le debía dos cortes de zapatos de cordobán ${ }^{75}$ y en ese mismo año Azencio, ya como maestro, admitió por aprendiz a Pascual muchacho, indio criollo de la ciudad. ${ }^{76}$

\section{La jerarquía en los artesanos emeritenses}

En Mérida, al igual que en otras regiones de América española, en las cuales los índices de densidad demográfica fueron modestos y en especial de la población blanca como en Caracas, ${ }^{77}$ Santiago de Chile ${ }^{78}$ y Buenos Aires, las instituciones gremiales no estuvieron presentes o se conformaron tardíamente en el siglo XVIII, aunque existieran artesanos ${ }^{79}$ con su correspondiente jerarquía, de acuerdo a su nivel de pericia y haber cumplido con los requisitos necesarios para alcanzarla. Los artífices emeritenses, se dividieron en cinco niveles jerárquicos, maestros, maestros examinadores, oficiales, obreros y aprendices. Los más numerosos fueron los

73 AGEM, Protocolos t.XII, Carta de fianza. Mérida, 22 de febrero 1631, f.68v.

74 AGEM, Protocolos t.XII, Concierto de servicio, Mérida, 20 de mayo de 1635, f.152v.

75 AGEM, Protocolos t.XXI, Testamento de Francisco Martín Gerena, Mérida, 18 de enero de 1652, ff.193v.-196r.

76 AGEM, Protocolos t.xxI, Concierto de Aprendiz, Mérida, 3 de junio de 1652, f.281v.

77 M. Pérez Vila, "El artesanado la formación de una clase media”, pp.332-333.

78 Julio Alemparte, "La regulación económica en Chile durante la colonia II", en Anales de la Facultad de Ciencias Jurídicas y Sociales vol.2, n. ${ }^{\circ}$, Santiago de Chile, Universidad de Chile, 1936.

79 M. Pérez Vila, "El artesanado la formación de una clase media”, p.334. 
aprendices, los que alcanzan el 41.7\% de la población estudiada (véase gráfico 2). Esto se debió a que debieron concurrir a las tiendas y talleres para asentarse para su aprendizaje con el maestro que les enseñara el oficio.

En ese sentido, las tiendas y talleres constituyeron centros de trabajo particulares donde se agruparon los artífices con distintos niveles de calificación, bajo la dirección de un maestro del oficio, quien usualmente fue propietario de las instalaciones y herramientas, los que constituían su capital y disponía de la comercialización de los productos. En esos centros laborales, se desarrollaba no sólo la producción de objetos, sino también el porceso de enseñanza-aprendizaje y se obtenía la destreza en el ejercicio de los oficios. Esa situación ocurrió debido a que en el interior de las tiendas y talleres laboraban artífices con diferentes niveles jerárquicos, encabezados por maestros, quienes dirigían a oficiales, ayudantes, obreros y aprendices, con los que mantenían vínculos laborales, extra laborales y hasta familiares. En tal virtud, tanto las autoridades de la ciudad como los padres de los jóvenes concurrían a las tiendas y talleres para $\operatorname{asentar}^{80}$ a los menores con los maestros para que aprendieran las labores, y al mismo tiempo los oficiales perfeccionaban su desempeño en el trabajo artesanal, estableciéndoles ciertos niveles de productividad, ${ }^{81}$ lo que les posibilitaba conseguir el rango de maestros.

De ese modo, cuando los aprendices habían completado su lapso de enseñanza recibían su uniforme y las herramientas de su oficio y asumían la jerarquía de oficiales. Inmediatamente se concertaban con algún propietario de una tienda o taller, por lo general un maestro, bajo cuya dirección realizaban su labor artesanal. Durante ese periodo, habitualmente recibían un salario en metálico, lo que les permitía ahorrar para continuar su ascenso. En la jerarquía artesanal, los oficiales, solo representan el $10.1 \%$ de los operarios registrados en Mérida durante los dos siglos estudiados (véase gráfico 2).

$80 \mathrm{Al}$ respecto se pueden mencionar asientos de aprendizaje, donde se establecía la obligación del aprendiz de laborar con el maestro para adquirir las destrezas propias del oficio, entre ellos el caso del oficial de zapatería Domingo Trujillo, quien en 1671, concertó por aprendiz del oficio a Feliz Santiago porque le primero tenía tienda pública en la plaza de la ciudad. AGEM, Protocolos t.XXXI, Asiento de aprendiz, Mérida, 25 de abril de 1671, f.55r.

81 En el concierto de servicio artesanal se estableció que Azencio de Carvajal, oficial de zapatero debería “... entregar dos pares de zapatos diarios y en vísperas de fiestas tres...”. AGEM, Protocolos t.XII, Concierto de servicio artesanal, Mérida, 20 de mayo de 1635, f.152v. 
Esa baja cifra está en relación con el proceso inmediato que debería cumplir el oficial para ascender en su escala jerárquica. Una vez que el oficial había ahorrado cierto dinero, procedía a solicitar los exámenes respectivos al cabildo para alcanzar la condición de maestro. El ayuntamiento encargaba realizar las respectivas pruebas al aspirante a los maestros debidamente acreditados y conocidos como "examinadores", que son los de menor incidencia con apenas el $2 \%$ del total estudiado (véase gráfico 2). Luego que el oficial presentaba las respectivas pruebas y probaba su experticia alcanzaba el rango de maestro del oficio y podía independizarse, establecer un taller propio, donde se dedicaba a elaborar sus productos, al mismo tiempo, recibía nuevos aprendices y oficiales.

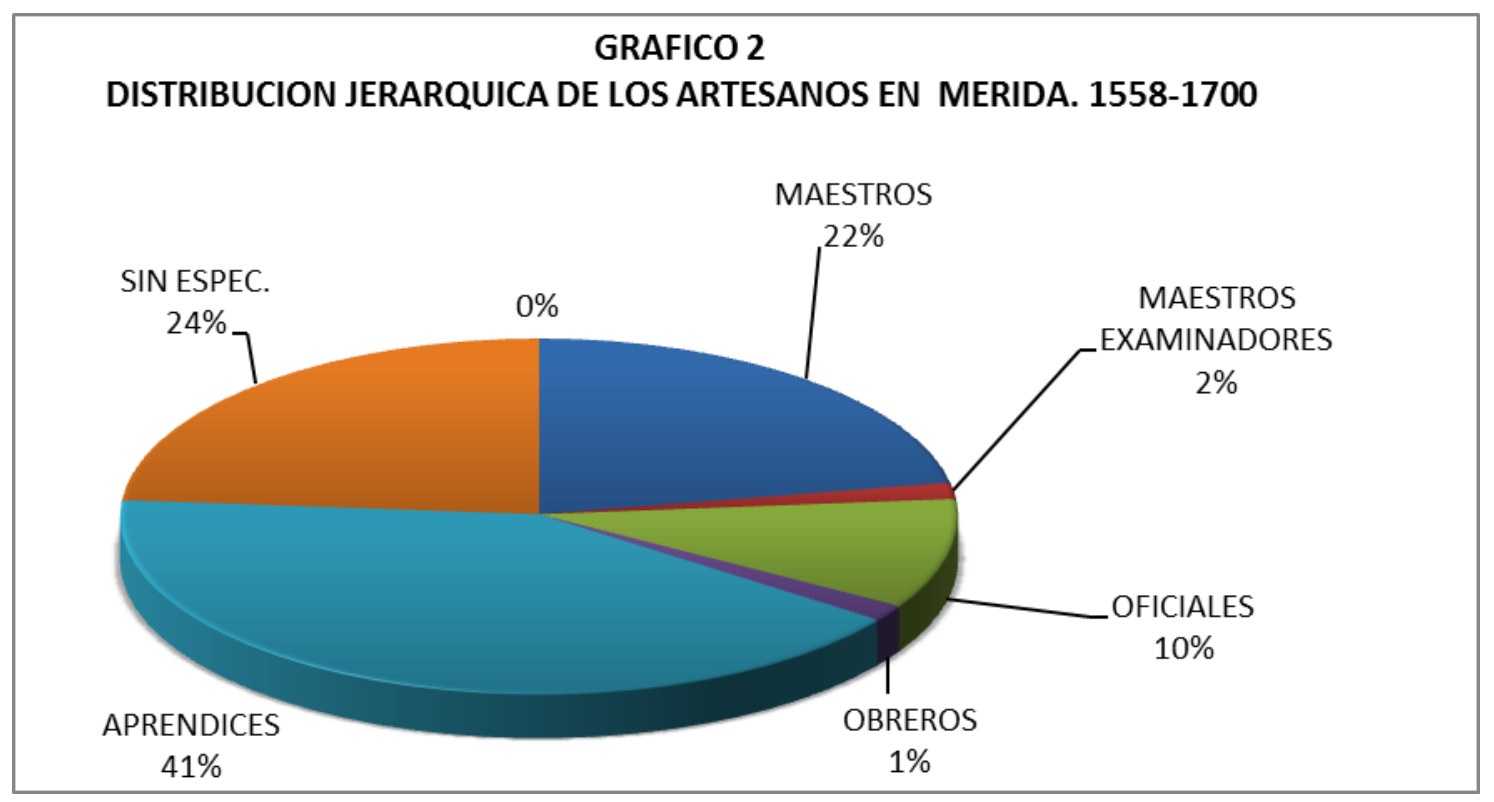

Fuente: AGEM, Protocolos ts. I-XL y Mortuorias t.I-X.

Para establecer el taller, el novel maestro debería contar con un local propio o arrendado donde se desarrollarían las tareas artesanales. ${ }^{82}$ Esporádicamente estos recintos fueron propiedad de los vecinos pudientes de la ciudad, quienes los

82 En 1581 Hernando de Cáceres, zapatero, se comprometió con Francisco Rodríguez, para “... asistir de ordinario en casa del dicho Hernando de Cáceres, trabajando en el dicho oficio, quanto en el fuere posible, cortando y cosiendo para él, como los demás mozos del dicho Hernando de Cázeres..." AGEM, Protocolos t.I, Carta de compañía, Mérida, 10 de febrero de 1581, f.194V. 
arrendaban o entregaban en administración a los artesanos. ${ }^{83} \mathrm{El}$ segundo requisito fue prestar las debidas fianzas establecidas por el cabildo emeritense, mediante las que el fiador se comprometía a garantizar el resguardo de las materias primas confiadas al artesano, como su procesamiento y la entrega de los productos solicitados, particularmente de aquellos que laboraban con metales preciosos. ${ }^{84}$

Asimismo, el fiador avalaba al artista garantizando que éste realizaría su obra, entregando "buena quenta" de las tareas que se le habían encargado. Del mismo modo el artesano se comprometía a no "hazer ausencia" de la ciudad hasta entregar los productos solicitados. ${ }^{85}$ Además, los garantes establecían el monto explícito en pesos por el cual respondían por el novel maestro y el lapso de duración de la fiaduría. Cuando el oficial hubiese cumplido con esos tres requisitos asumía plenamente la jerarquía de maestro, los que alcanzaron el $22.4 \%$ del total de la población artesana emeritense (véase gráfico 2).

En aquellos casos que los artesanos incumplieran con las responsabilidades contraídas fueron objeto de duras sanciones por la justicia ordinaria, que disponía el encarcelamiento inmediato de los artífices. Para que los operarios pudieran abandonar los reclusorios fue necesaria nuevamente la presentación de las fianzas, el establecimiento preciso de la forma de cumplimiento de las obligaciones adqui-

83 En un testimonio de 1656, se expresa que el capitán Pedro de Gaviria Navarro, concertó con Pedro López Mexía, maestro de platero “...para la disposición de una tienda en esta ciudad en la cantidad que contuviere el concierto, que fue su voluntad se la tomó en quenta de lo que ha ido a su cargo y se cobre el alcanze de lo que hubiere..." AGEM, Protocolos t.XXIII, Testamento por poder del Capitán Pedro Gaviria Navarro, Mérida, 25 de mayo de 1657, ff.68v-89r.

84 Al parecer las fianzas por cantidades más elevadas las debían presentar los plateros, como sucedió en 1629, cuando Antonio de Aranguren prestó fianza a favor del platero Juan Cordero de Trexo por quinientos pesos de ocho reales castellanos, para garantizar que el artesano daría “... quenta de las obras que le dieren a hazer y no hará ausencia de esta dicha ciudad sin aver satisfecho a los du eños de ellas..." AGEM, Protocolos t.XII, Carta de fianza, Mérida, 19 de abril de 1629, f.420r.

85 En 1665, Luis Sánchez, vecino de Mérida otorgó un carta de fianza a favor de Joseph de Rojas vecino de Mérida y maestro de zapatería “...en tal manera que el dicho Joseph de Rojas tendrá tienda pública donde trabajar su dicho oficio (de zapatero) para buena quenta del pago de dichas obras, cordovanes y zuelas que se le dieran para sus obras...” AGEM Protocolos t.XXV, Carta de fianza, Mérida, 20 de noviembre de 1665, f.264v. En 1665, Luis Sánchez, vecino de Mérida otorgó un carta de fianza a favor de Joseph de Rojas vecino de Mérida y maestro de zapatería “...en tal manera que el dicho Joseph de Rojas tendrá tienda pública donde trabajar su dicho oficio (de zapatero) para buena quenta del pago de dichas obras, cordovanes y zuelas que se le dieran para sus obras...” AGEM, Protocolos t.xxv, Carta de fianza, Mérida, 20 de noviembre de 1665, f.264v. 
ridas y defraudada al igual que se definió el lapso temporal en el que se cumplirían los compromisos contraídos. ${ }^{86}$

En Mérida colonial, las tiendas y talleres artesanales hicieron su aparición tempranamente desde el siglo XVI y debieron su origen a la particularidad de ciertos operarios, como los zapateros, sastres, plateros, caldereros, silleros y carpinteros quienes podían desplegar sus labores libremente en el centro de la urbe con fines comerciales, ${ }^{87}$ porque esas artesanías no producían desechos contaminantes o malolientes.

Las actividades artesanales desarrolladas en las tiendas y talleres fueron variadas, en 1580, Manuel Pimienta tenía una tienda donde producían sobreros, ${ }^{88}$ mientras Alonso de Rojas entre 1628 y 1635 también regentó otra del mismo oficio,

86 En 1645, Juan de Castillo Ángel, maestro de joyero otorgó fianza a favor de Juan Estevan de Ochoa, oficial de joyero, a quien el Padre Julio Ledi, Rector de la Compañía de Jesús, le había entregado siete pesos de oro de veinte y dos quilates para la realización de obras, las cuales no había efectuado, por ello estaba apresado, el fiador se comprometió a pagar al religioso dos patacones semanales hasta la cancelación definitiva de la deuda. AGEM, Protocolos t.XXVIII, Carta de fianza, Mérida, 30 de septiembre de 1645, f.244r-v. Igualmente en 1664, Francisco Coriano, vecino de Mérida, maestro de curtidor, otorgó fianza a favor de Francisco de Venegas, encarcelado a petición de Francisco Márquez, oficial de zapatero, quien le había entregado diez cordobanes y adicionalmente cuatro que debía a Esteban de Aguado, por ambas deudas, Francisco Benegas, se obligó a pagar 25 pesos en obras del oficio. AGEM, Protocolos t.XXVI, Carta de fianza, Mérida, 8 de julio de 1664, f.85r.-v. Igualmente, en 1665, Juan Francisco Martínez, residente en Mérida, Antonio de Luna y María Martínez, viuda e indios criollos, prestaron una fianza a favor de Diego de La Cruz, zapatero vecino de Mérida y encarcelado por “... débitos que son de Agustín Durán de la Parra de veinte y seis patacones y seis reales, que proceden de veinte cordovanes que le dio para hazer obras y a Luis Sánchez, vecino de esta ciudad, le debe treinta patacones y seis reales, por lo cual se comprometen a pagar a los dichos Diego Durán y Luis Sánchez dos patacones dos patacones... cada semana y otro al dicho Luis Sánchez, pagado los domingos de cada semana y para la seguridad de ellos les hipotecan el dicho Francisco Martínez las herramientas de su oficio de zapatero, y el dicho Antonio Juan un macho de carga y bueno de color negro y la dicha María Martínez dos solares que tiene por lo bajo de esta ciudad...” AGEM, Protocolos t.XXVII, Carta de fianza, Mérida, 17 de julio de 1666, ff.60v.-62v.

87 Las tiendas en las ciudades coloniales fueron ubicadas cercanas a la plaza mayor, de acuerdo a lo establecido en las ordenanzas de Felipe II, en las que se dispuso "... en la plaza no se den solares a particulares, dense para la fabrica de la iglesia y casas reales y propios de la ciudad y edifíquense tiendas y casas para tratantes y sea lo primero que se edifique para lo qual contribuyan todos los pobladores..." Archivo General de Indias (AGI, Indiferente General, leg.427, Libro XXIX. Ordenanzas de descubrimiento, nueva población y pacificación de las Indias dadas por Felipe II. Bosques de Segovia, 18 de julio de 1573. Ordenanza 125. f.89r.

88 AGEM, Protocolos t.I, Asiento de aprendiz, Mérida, 3 de junio de 1580, f. 53r. 
donde trabajaron dos aprendices. ${ }^{89}$ Igualmente en el oficio de zapatero, se reseña en 1581, a Hernando de Cáceres, quien tenía un taller en su casa donde había "mozos y aprendices" trabajando en el oficio. ${ }^{90}$

Posteriormente, entre 1615 y 1622, Juan Rodríguez Tamayo maestro de zapatero, ocupó en su tienda a dos aprendices, ${ }^{91}$ mientras Andrés de Luna, maestro del mismo oficio entre 1625 y 1637 tuvo cuatro neófitos ${ }^{92}$ y dos oficiales en su tienda. ${ }^{93}$ Otro zapatero que desplegó sus labores en Mérida, fue Joseph de Roxas, ${ }^{94}$ quien inició sus labores en su taller aproximadamente en 1660, como lo acredita la fianza otorgada en su favor por Luis Sánchez en $1663,{ }^{95}$ allí se desempañaron por alumnos dos huérfanos Antonio Lobo y Felipe Díaz. ${ }^{96}$ Otros zapateros que también tuvieron tiendas fueron Domingo de Trujillo, ${ }^{97}$ Francisco de la Peña ${ }^{98}$ y Diego de la Cruz. .99

89 Los aprendices de Alonso Rojas fueron Felipe natural de Suata AGEM, Protocolos t.XI, Asiento de aprendiz, Mérida, 24 de abril de 1629. f.379r. y Lope AGEM, Protocolos t.XI, Asiento de aprendiz, Mérida, 1 de septiembre de 1628, f.316r.

90 AGEM, Protocolos t.I, Carta de compañía, Mérida, 10 de febrero de 1581, f.194v.

91 AGEM, Protocolos t.IV, Asiento de aprendiz. Mérida, 28 de enero de 1615. f. 297v. AGEM, Protocolos t.viII, Asiento de aprendiz, Mérida, 18 de agosto de 1622, f.5oor

92 Los aprendices de Andrés de Luna fueron, Juan Gaviria por 6 años. AGEM, Protocolos t.Iv, Asiento de aprendiz, Mérida, 28 de enero de 1615, f.297v.; AGEM, Protocolos t.VIII, Asiento de aprendiz, Mérida, 21 de enero de 1623, f.35v. Pedro criollo por 3 años, AGEM, Protocolos t.IX, Asiento de aprendiz, Mérida, 12 de agosto de 1627, f.228r.-v. Bernabé García por 3 años, AGEM, Protocolos t.IX, Asiento de aprendiz, Mérida, 31de julio de 1628, f.308r. y Joan por 3 años, AGEM, Protocolos t.XIV, Asiento de aprendiz, Mérida, 23 de abril de 1637, f.125v.

93 Los oficiales fueron Francisco Hernández por un año. AGEM, Protocolos t.XII, Concierto de servicio artesanal, Mérida, 23 de octubre de 1628, f.246v., y Azencio de Carvajal por un año, AGEM, Protocolos t.XIV, Asiento de aprendiz, Mérida, 23 de abril de 1637, f.125v.; AGEM, Protocolos t.XII, Concierto de servicio artesanal, Mérida, 20 de mayo de 1635, f.152v.

94 AGEM, Protocolos t.XII, Carta de fianza. Mérida, 20 de noviembre de 1665, f.265r.

95 AGEM, Protocolos t.XII,Carta de fianza, Mérida, 19 de abril de 1629, f.420r.; AGEM, Protocolos t.XII, Asiento de aprendiz, Mérida, 20 de noviembre de 1663, f.265v.

96 Agem, Protocolos t.xxix, Asiento de aprendiz, Mérida, 25 de abril de 1671, f.55v

97 AGEM, Protocolos t.XXIX, Asiento de aprendiz, Mérida, 5 de febrero de1672, f.198r.

98 AGEM, Protocolos t.XIX, Asiento de aprendiz, Mérida, 13 de noviembre de 1646, f.132v.

99 AGEM, Protocolos t.XX, Asiento de aprendiz, Mérida, 29 de septiembre de 1648, f.13or. 
Otra tienda en la que se desarrolló una interesante actividad fue la del platero Juan Cordero de Trexo, quien inició sus labores aproximadamente en la tercera década del siglo XVII, de acuerdo con la fianza otorgada en su favor por Antonio de Aranguren, hasta por 500 pesos de plata de ocho reales castellanos, entre $1646 \mathrm{y}$ 1677. El platero tuvo en su tienda por aprendices a Bartolomé Castillo, ${ }^{100}$ Pedro, Agustín Patiño, Tomás Vernal, Lorenzo Vazán, y sus sobrinos Francisco de Trejo y Juan de Trejo. ${ }^{101}$ Por su parte Juan Castillo Ángel, un maestro joyero, poseyó una tienda, en la cual desarrollaba su labor con un oficial llamado Juan Estevan de Ochoa en $1645 \cdot \cdot^{102}$

Del mismo modo, las carpinterías están presentes en Mérida desde el siglo XVI, y adquirieron mayor auge en la centuria siguiente. En 1623 Diego Román y Juan Muñoz Criptana (padre) hicieron una compañía en la cual los dos se comprometían a "meter un mozo”. ${ }^{103}$ Por esa razó, meses después Diego Román asentó por aprendiz a Juan Bautista ${ }^{104}$ y en 1626, ingresó bajo su dirección un mestizo llamado Francisco. ${ }^{105}$ Otro carpintero que desplegó una especial actividad fue Mateo Leal, quien también era ensamblador, en 1650, se le encargó la construcción de la iglesia de la Compañía de Jesús, ${ }^{106}$ en su taller laboraban dos aprendices uno llamado Bartolo, huérfano ${ }^{107}$ y Salvador de Gutiérrez. ${ }^{108}$ Otro carpintero digno de

100 AGEM, Protocolos t.xXVI, Asiento de aprendiz, Mérida, 21 de noviembre de 1663, f.266v.

101 AGEM, Protocolos t.XXXIII, Asiento de aprendiz, Mérida, 6 de octubre de 1677, f.99v.; AGEM, Protocolos t.XXXIII, Asiento de aprendiz. Mérida, 6 de octubre de 1677, f.99v.

102 En la Carta de obligación se expresa que “... y estando presente el dicho Juan Estevan de Ochoa, dixo que se obligaba y se obligó a travaxar en la tienda del dicho Juan Castillo Ángel en el dicho oficio (joyero)...” AGEM, Protocolos t.XVIII, Carta de obligación de joyero, Mérida, 30 de septiembre de 1645 , f.24r-v.

103 AGEM, Protocolos t. XIX, Carta de Compañía, Mérida, 9 de mayo de 1623, f.632v.

104 AGEM, Protocolos t.VIII, Asiento de aprendiz, Mérida, 11 de enero de 1624, f.668v.

105 AGEM, Protocolos t. X, Asiento de aprendiz, Mérida, 15 de abril de 1626, f.91r.

106 AAM, Seminario Caja 1 Inventario de los papeles del Colegio de San Francisco Xavier de la Compañía de Jesús, 1775, f.19v.

107 AGEM, Protocolos t.XXIv, Asiento de aprendiz, Mérida, 7 de febrero de 1660, ff.14v-15v.

108 AGEM, Protocolos t.XIX, Asiento de aprendiz, Mérida, 19 de noviembre de 1665, f.261r.-v. 
reseñar fue Juan Muñoz Criptana hijo, quien construyó el altar a la Virgen de la Chiquinquirá en la capilla menor del Convento de Santa Clara. ${ }^{109}$

Otra labor que se realizó en las tiendas artesanales de Mérida colonial fue la sastrería, en la cual se destacan dos sastres de aproximadamente 80 artesanos que se dedicaron a ese trabajo, uno es Francisco de Osuna, quien estuvo activo entre la tercera y cuarta década del siglo XVII, en 1627, se concertó con Diego Varela Graterol para enseñarle su esclavo, llamado Antonio, oriundo del Brasil, ${ }^{110}$ en 1628 tomó por aprendiz a Juan Martínez ${ }^{111}$ y en 1657 a Luis Sánchez. ${ }^{112} \mathrm{Al}$ igual que el anterior artesano, Pedro Ponce de San Martín fue un activo sastre que entre 1647 y 1669 desplegó su actividad artesanal en una tienda donde laboraron como aprendices cuatro niños huérfanos, Mateo, ${ }^{113}$ Joseph, ${ }^{114}$ Felipe ${ }^{115}$ y Pedro, ${ }^{116}$ también trabajaron con este sastre Juan Rodríguez ${ }^{117}$ y Fabián Pérez. ${ }^{118}$

Por otra parte, las tiendas de sillería y talabartería también fueron comunes en Mérida en los primeros siglos coloniales, en 1624, Baltasar de los Reyes, maestro de ese oficio tuvo por ayudante a Bartolomé ${ }^{119}$ y por aprendices a un mulato también llamado Baltasar de los Reyes ${ }^{120}$ y a Jacinto. ${ }^{121}$ Otros silleros y talabarteros que tuvieron tiendas fueron Esteban de Aguado y Juan de Montoya. Finalmente hay que reseñar los artesanos que no especifican su rango, los que ascienden al $24 \%$ del total.

109 AgEM, Protocolos t.XXXV, Testamento de Juan Muñoz Criptana hijo. Mérida, 1 de abril de 1690. ff.223v.-226r.

110 AGEM, Protocolos t.XI, Concierto de enseñanza, Mérida, 27 de septiembre de 1627, f.238v.

111 AGEM, Protocolos t.XII, Asiento de aprendiz, Mérida, 29 de noviembre de 1628, f.237v.

112 AGEM, Protocolos t.XIX, Asiento de aprendiz, Mérida, 22 de abril de 1637, f.116r.

113 AGEM, Protocolos t.XIX, Asiento de aprendiz, Mérida, 20 de agosto de 1647, ff.144v.-145r.

114 AGEM, Protocolos t.XX, Asiento de aprendiz, Mérida, 10 de mayo de 1648, f.69v.

115 AGEM, Protocolos t.XXIV, Asiento de aprendiz, Mérida, 24 de septiembre de 1658, f.101r.

116 AGEM, Protocolos t.XXVIII, Asiento de aprendiz, Mérida, 9 de mayo de 1669, f.70v.

117 AGEM, Protocolos t.XXVII, Asiento de aprendiz, Mérida, 20 de junio de 1668, ff.195v.-196r

118 AGEM, Protocolos t.XXV, Asiento de aprendiz, Mérida, 5 de septiembre de 1662, f.101v.

119 AGEM, Protocolos t.viII, Asiento de aprendiz, Mérida, 12 de junio de 1624, f.679v.

120 AGEM, Protocolos t.IX, Asiento de aprendiz, Mérida, 30 de enero de 1627, ff.187v.-188r.

121 AGEM, Protocolos t.XI, Asiento de aprendiz, Mérida, 11 de octubre de 1627, f.239v. 


\section{La esclavitud}

Adicionalmente al concierto artesanal, también se utilizó la esclavitud, ${ }^{122}$ para efectuar el trabajo artesanal. En Mérida, al igual que otras ciudades de Hispanoamérica, se destinaron esclavos para producir artesanías. Los esclavos constituyeron bienes semovientes de sus propietarios y por ende carecían de personería jurídica para decidir sobre sus actividades e inclusive su vida. ${ }^{123}$ En ese sentido, la decisión y los intereses de sus propietarios fueron determinantes para seleccionar las actividades que éstos desempeñaron. Evidentemente la adquisición de un esclavo, llevaba implícitamente la intención de destinar su fuerza laboral a una determinada tarea y por ende obtener un beneficio ulterior.

Por ello, en el desarrollo de las actividades agrícolas y pecuarias en los núcleos de producción, se requirió de mano de obra especializada destinada a elaborar utensilios para realizar esos implementos tales como azadas, arados, rejas, herramientas en general, cuchillos, palas, herraduras, espuelas, jáquimas, sillas de montar y otros logrando cierto nivel de autosuficiencia. Con ello se evitó, la adqui-

122 Germán Colmenares, Historia económica y social de Colombia II. Popayán una sociedad esclavista. 1680-18oo, Bogotá. Ed. La Carreta, 1979; Nicolás del Castillo Matheiu, Esclavos negros en Cartagena y sus aportes léxicos, Bogotá, Instituto Caro y Cuervo, 1982; Ildefonso Gutiérrez Azopardo, Historia del negro en Colombia ¿̇sumisión o rebeldía?, Bogotá, Nueva América, 1980; Jorge Palacios Preciado, Cartagena de Indias, gran factoría de la mano de obra esclava, Tunja, Eds. Pato Mariño, 1975, y La trata de negros por Cartagena de Indias, Tunja, Universidad Pedagógica y Tecnológica de Colombia, 1973; Carlos Valencia Villa, Alma en boca y huesos en costal. Una aproximación a los contrastes socio-económicos de la esclavitud, Santa Fe, Mariquitá y Mompox, Bogotá, ICANH, 2003; William F. Sharp, "La rentabilidad de la esclavitud en el Chocó 1610-1810", en Anuario Colombiano de Historia Social y de la Cultura n. ${ }^{\circ}$, Bogotá, Universidad Nacional, 1987, pp.1945, María C. Navarrete, Génesis y desarrollo de la esclavitud en Colombia Siglos XVI y XVII, Cali, Universidad del Valle, 2005; Daniel P. Manix y M. Cowley, Historia de la trata de negros, Madrid, Alianza Ed., 1970; Frederick P. Browser, El esclavo africano en el Perú colonial (1524-1650), México, Siglo XXI Eds., 1977, pp.48 y ss.; Miguel Acosta Saignes, Vida de los esclavos negros en Venezuela, Caracas, Ed. Hespérides, 1970; John Lombardi, Decadencia y abolición de la esclavitud en Venezuela. 1820-1854, Caracas, Universidad Central de Venezuela, 1974; Ermila Troconis de Veracoechea, Documentos para el estudio de los esclavos negros en Venezuela, Caracas, Academia Nacional de la Historia, 1969; Edda Samudio, "Los esclavos de las haciendas del colegio San Francisco Xavier de Mérida”, en Separata de la revista Paramillo n. ${ }^{\circ}$ 17, San Cristóbal, Universidad Católica del Táchira, 1998, p.432; Federico Brito Figueroa, El problema tierra y esclavos en la Historia de Venezuela, Caracas, Asamblea Legislativa del Estado Aragua, 1973; Zoraida Santiago, Aspectos de la esclavitud en Mérida 1775-18oo, Mérida, (tesis) Universidad de Los Andes, 1981.

123 José María Ots Capdequí, Historia del Derecho español en América y del Derecho Indiano, Madrid, Aguilar, 1968, pp.211 y ss. 
sición de esas herramientas a proveedores foráneos. Por el contrario se obtenían al ser fabricadas por los esclavos artesanos en las unidades de producción con la consiguiente reducción de costos e igualmente se evitaba el retraso en las labores productivas. Con aquellos objetivos no es extraño que los esclavistas procedieran a asentar sus esclavos para que éstos adquirieran las destrezas necesarias de los operarios, mediante lo cual obtendrían mano de obra calificada, al mismo tiempo que aumentaban el valor de los mismos.

En Mérida, desde el siglo XVI, están presentes testimonios sobre la existencia de esclavos que cumplían el trabajo artesanal, en 1592, Martín Fernández vecino de Trujillo, concertó a Gonzalo García de la Parra, herrero de Mérida para que enseñara el oficio a un negro esclavo de su propiedad, de quince años, de nación conga, llamado Juan.124 Años más tarde, en 1613, Hernando Cerrada, conquistador y encomendero de los Timotes, hizo donación de un negro esclavo, herrero, de nación criollo a su hijo Juan Cerrada, con la fragua, y los aparejos del oficio. ${ }^{125}$ Por su parte, el gobernador Juan Pacheco y Maldonado, concertó a Cristóbal de Xaramillo, herrero, para que enseñara dos de sus negros, expresando que los esclavos estaban obligados a aprender todo lo relacionado con la fragua a fin de realizar las obras de las estancias y haciendas del mismo como, rejas herramientas y calzaduras. ${ }^{126}$ Entre tanto, en otro concierto suscrito entre el gobernador y Andrés Vázquez, zapatero, quién se comprometió a instruir en el oficio a un negro esclavo de Pacheco, llamado Pedro fuerte, el esclavo debería aprender a cortar y coser calzado durante 2 años y Andrés Vázquez recibiría treinta pesos en pago de su servicio. ${ }^{127}$

En otro concierto entre Diego Varela Graterol vecino de Trujillo, con Pedro Fernández Oxeda, herrero vecino de Mérida, mediante el cual el artesano se comprometió a adiestrar a un mulato esclavo del primero en el oficio de herrero y cerrajero, por tres años consecutivos. El herrero recibiría en pago de la instrucción que le diera al esclavo setenta y cinco pesos, ${ }^{128}$ al parecer el oficio de herrero fue

\footnotetext{
124 AGEM, Protocolos t.II, Asiento de aprendiz de herrero, Mérida, 27 de mayo de 1592, f.120v.

125 AGEM, Mortuorias t.I, Testamento e ynventario del Capitán Fernando Cerrada vezino de esta ciudad de Mérida fechado a doze de henero de 1613, Testamento. Trujillo, 11 de enero de 1613, ff.1r.$14 \mathrm{v}$.

126 AGEM, Protocolos t.XIII, Asiento de Aprendiz de herrero, Mérida, 18 de junio de 1632, f.125r.

127 AGEM, Protocolos t.X, Asiento de aprendiz de zapatero, Mérida, 9 de abril de 1627, f.199v.

128 AGEM, Protocolos t.X, Asiento de aprendiz de herrero, Mérida, 27 de septiembre de 1627, f.237v.
} 
importante para los esclavistas. Igualmente, Diego Varela Graterol, concertó a Francisco de Osuna, sastre, para que le aleccionara en el oficio a un negro esclavo suyo, llamado Antonio, oriundo del Brasil, por dos años. ${ }^{129}$

Por otra parte, el duro trabajo, tal vez los castigos y maltratos a que fueron sometidos los esclavos artesanos por sus propietarios propiciaron sus fugas. Uno de esos casos fue el de Francisco negro, oficial de curtidor, que se había huido y estaba preso en la cárcel de la ciudad de Carora, gobernación de Venezuela, por lo cual su dueño, Francisco Uzcátegui Reolid extendió un poder a Domingo de Vargas, para venderlo en 1643.130 En otro caso, es el reseñado entre los herederos del Capitán y Sargento Mayor García de Rivas, donde se hizo una carta de aclaratoria de bienes, expresamente destinada a deducir el valor de un esclavo llamado Nicolás, carpintero, fugitivo en la gobernación de Venezuela al que sus propietarios, se propusieron aprenderlo y venderlo. ${ }^{131}$

\section{Origen y procedencia de los artesanos merideños}

La población que concurrió al mercado laboral del concierto artesanal en sus dos modalidades de obra y servicio se nutrió en primera instancia por los naturales de la región, luego por la creciente población desposeída y desarraigada de sus lugares de origen, conformada por blancos que tardíamente habían llegado a la ciudad, ${ }^{132} \mathrm{e}$ indios procedentes de otras regiones, ${ }^{133}$ al igual que mestizos zambos, negros libres $^{134}$ y esclavos, integrando un mosaico interétnico que acudió a la legalización de

129 AGEM, Protocolos t.XI, Concierto de aprendiz de sastre, Mérida, 27 de septiembre de 1627, f.238v.

130 AGEM, Protocolos t.XIII, Carta de poder, Mérida, 30 de septiembre de 1643. f.88r.

131 AGEM, Protocolos t.XXI, Carta de aclaratoria de las mandas Testamentarias del Capitán y Sargento Mayor García de Rivas, Mérida, 20 de junio de 1652. ff.293r-294v.

132 AGEM, Protocolos t.XIII, Testamento de Alonso Muñoz Daza, Mérida, 18 de marzo de 1632, ff.70r.-78r.

133 Entre otros se puede señalar a Alonso Muñoz Daza, carpintero de trapiches, natural de Manzanilla, jurisdicción del Arzobispado de Sevilla, mientras Cristóbal de Salinas, era un indio oficial de sastre procedente de Muzo, quien en 1666, canceló el requinto de forasteros. AGNC, Real Hacienda, Cuentas t.396c- y 452c. Cajas Reales de Mérida t.I, Requintos de Forasteros. Mérida, 2 de junio de 1666, f.12r.

134 En 1661 se asentó por aprendiz de zapatero a Ventura mulato libre con Pedro Varón, maestro de sastre, haciéndose mención a que el mulato era hijo de Victoria, negra y que ambos habían sido 
conciertos desde el siglo XVI. La información demográfica del artesanado emeritense, permite afirmar que asciende aproximadamente a cuatrocientos noventa y un individuos, distribuidos en veinticuatro oficios distintos (véase tabla 3), en los cuales no se incluyen los indígenas, que como ya se ha señalado, realizaban labores artesanales, fundamentalmente textiles, en los pueblos de indios, sometidos al régimen de encomiendas, quienes incrementarían notoriamente esas cifras, de las que no se dispone información precisa.

Sin embargo, la cuantía obtenida, resulta altamente significativa, si se compara con los índices demográficos que se conocen sobre Mérida durante el periodo estudiado. Al respecto Diego de Villanueva y Gibaja, refiere que la ciudad tenía, aproximadamente 120 vecinos en $1607^{135}$ a los que se debe agregar la población indígena, calculada según las estimaciones de Vásquez de Cisneros en 1620, en 10.114, indios, de los que aproximadamente, 3000 eran útiles y tributarios. ${ }^{136}$ Estos índices, permiten pensar, en una aproximación de unos 11.00o, habitantes, incluyendo los esclavos, las familias de los blancos, y la creciente población mestiza y forastera.

De acuerdo con esas cifras, población artesana, del período se acercaría entonces a un $10 \%$ de la población económicamente activa estimándola aproximadamente en 4.000 personas, incluyendo indios, blancos y esclavos. Sin embargo, es necesario ser prudentes con estos índices, pues en ellos se excluyen las mujeres indias y blancas que también participaron directamente en el proceso productivo. A pesar de ello, se puede considerar que la población artesana era significativa dentro en el contexto económico del periodo estudiado.

esclavos de Isabel Gutiérrez. AGEM, Protocolos t.xxv, Asiento de aprendiz. Mérida, 3 de junio de 1661, f.76r.

135 "Relación geográfica hecha por Diego de Villanueva y Gibaja de la Gobernación de Venezuela, Los Corregimientos de La Grita y Tunja y la Gobernación de los Mussos año de 1607”, en Antonio Arellano Moreno (comp.), Relaciones geográficas de Venezuela, Caracas Academia Nacional de la Historia, 1964, p.204.

136 AGNC, Visitas de Venezuela t.II, Visita de Alonso Vásquez de Cisneros a Mérida (Ordenanzas) Mérida, 17 de agosto de 1620, ff.833 y ss. 
Tabla 3: Distribución jerárquica de los artesanos por oficio en Mérida. 1558-1700

\begin{tabular}{|c|c|c|c|c|c|c|c|}
\hline Oficio & Maestro & $\begin{array}{c}\text { maestro } \\
\text { examinador }\end{array}$ & oficial & obrero & aprendiz & $\mathbf{s} / \mathbf{e}$ & total \\
\hline albañiles & 6 & & 2 & & 6 & 8 & 22 \\
\hline batihojas & 1 & & & & 1 & & 2 \\
\hline calderero & 1 & & & & 1 & & 2 \\
\hline carpinteros & 11 & & 3 & & 14 & 20 & 48 \\
\hline $\begin{array}{l}\text { carpintero y } \\
\text { ensamblador }\end{array}$ & 2 & & 1 & & 2 & 1 & 6 \\
\hline cantero & & & 1 & & & & 1 \\
\hline cerrajero & 1 & & & & 2 & & 3 \\
\hline cerero & 2 & & & & 2 & & 4 \\
\hline curtidor y zurrador & 4 & & 2 & & 6 & 10 & 22 \\
\hline cuchillero & 1 & & & & 1 & & 2 \\
\hline escultor & 1 & & & & 1 & & 2 \\
\hline espadero & 3 & & & & 3 & 1 & 7 \\
\hline herrero & 12 & & 6 & & 24 & 12 & 54 \\
\hline joyeros & 1 & & 1 & & & & 2 \\
\hline labrandera & & & & & & 5 & 5 \\
\hline platero & 3 & & 1 & & 10 & 4 & 18 \\
\hline pintor & 1 & & & & 1 & 1 & 3 \\
\hline sastre & 22 & 2 & 3 & 1 & 45 & 10 & 83 \\
\hline sillero & 5 & & 4 & & 15 & 4 & 28 \\
\hline sombrerero & 1 & & & & 6 & 2 & 9 \\
\hline tejedor & & & & & & 4 & 4 \\
\hline tejero & 2 & & & 6 & 1 & & 9 \\
\hline teñidor & & & & & & 5 & 5 \\
\hline zapatero & 75 & & 12 & & 63 & & 150 \\
\hline Total & 155 & 2 & 36 & 7 & 204 & 87 & 491 \\
\hline
\end{tabular}

Fuente: AGEM, Protocolos ts. I-XL y Mortuorias t.I-X.

La conformación de la población artesanal presenta dos etapas, inicialmente, se nutrió del grupo poblacional que promovió el proceso de ocupación y asentamiento en el territorio de las Sierras Nevadas. Concurrentemente con la fundación de Mérida se avecindaron en la ciudad población proveniente de Europa y el Nuevo Reino de Granada. ${ }^{137}$ Durante las primeras décadas coloniales, hubo artesanos de origen europeo, como el herrero Antón Corzo, natural de la isla de Córcega, ${ }^{138}$ y su hijo Juan mientras Sebastián Alonso, el portugués, fue aprendiz de som-

137 Roberto Picón Parra, Fundadores, primeros moradores y familias coloniales de Mérida, ts.I-II, Caracas, Academia Nacional de la Historia, 1988.

138 AGEM, Protocolos t. I, Reconocimiento de deuda, Mérida, 25 de mayo de 1578, f.120v. 
brerero $^{139}$ al igual que Rodrigo Alonso, natural de Segura, en el Reino de León, también aprendiz de sombrerero. ${ }^{140} \mathrm{~A}$ pesar de ello, la población blanca dedicada al ejercicio de los oficios artesanales fue reducida y sólo alcanza el 1.69\% del total estudiado (véase gráfico 3).

Durante la segunda mitad del siglo XVI, y primeras décadas del XVII, se han identificado artesanos procedentes del Nuevo Reino de Granada. Esos trabajadores reconocen que son originarios de Santa Fe, Tunja, Duitama, Suata, Salazar de las Palmas entre otras localidades y alcanzan un $10.3 \%$ de la población estudiada. (Véase gráfico 1) $\mathrm{Al}$ parecer, éstos fueron indígenas fugitivos de las duras jornadas de trabajo a las cuales fueron sometidos por los encomenderos en las minas y obrajes del Nuevo Reino de Granada. ${ }^{141}$ Entre tanto, de la Gobernación de Venezuela provino una reducida población que se dedicó a las labores artesanales con un $2.41 \%$ del total estudiado (véase gráfico 3).

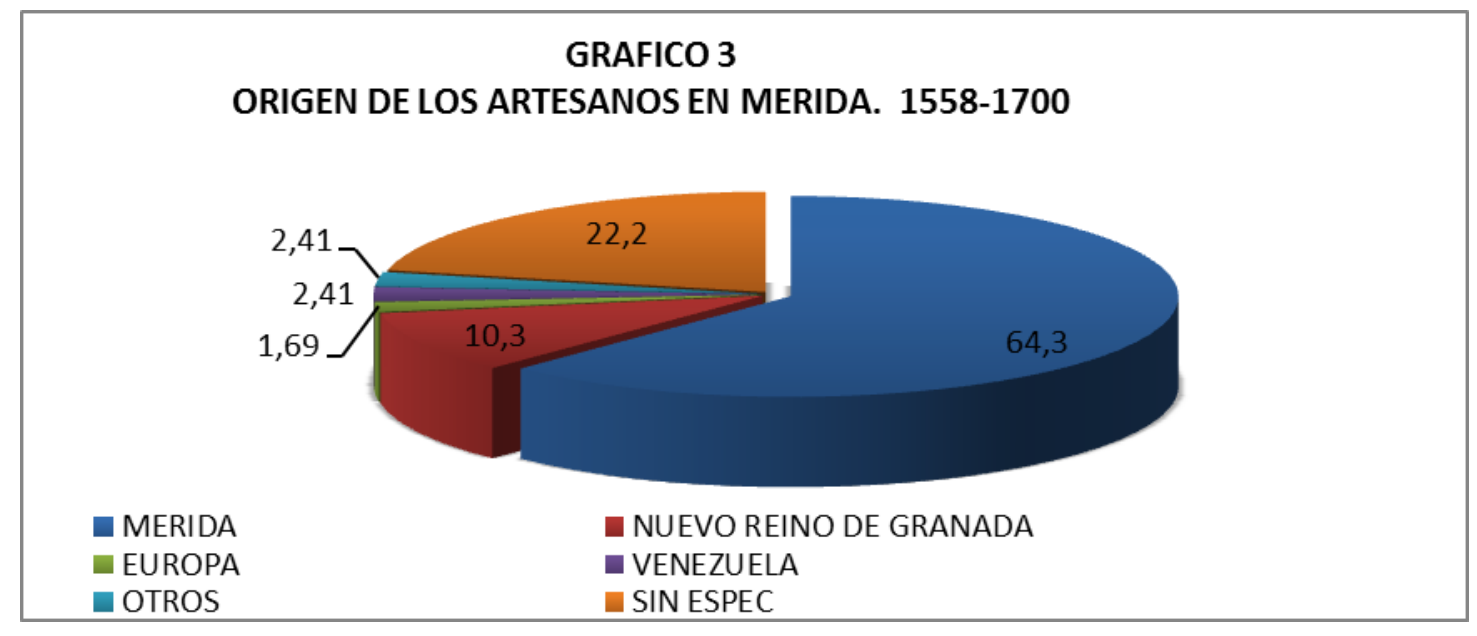

Fuente: AGEM, Protocolos T. I-XL y Mortuorias T. I-X.

También, es necesario señalar que hubo esclavos artesanos cuyo origen se reseña en el Congo y Brasil. Los artífices foráneos estuvieron obligados a pagar el requinto

\footnotetext{
139 AGEM, Protocolos t.I, Concierto, Mérida, 3 de junio de 1580, f.154r.

140 AGEM, Protocolos t.I, Testamento de Rodrigo Alonso, Mérida, 16 de noviembre de 1581, f.244r.

141 Edda Samudio, "El concierto agrario", en El trabajo y los trabajadores en Mérida Colonial. Fuentes para su Estudio, San Cristóbal, Universidad Católica del Táchira, 1988, p.139.
} 
de forasteros, ${ }^{142}$ pero la mayoría de los artesanos tuvieron su origen en Mérida y su área de jurisdicción con un $63 \%$ de la población estudiada, mientras no especifican su origen un $22.2 \%$ (véase gráfico 3 ).

\section{Grupos étnicos en el artesanado merideño}

La presencia de un grupo invasor en la región andina y su establecimiento, generó que en la cordillera merideña se iniciara un intenso proceso de mestizaje, el cual fue ampliamente extendido, En las grandes ciudades hispanoamericanas, los artífices se agruparon en gremios y corporaciones, que tuvieron rigurosas disposiciones legales para su funcionamiento y admisión. Fundamentalmente la principal preocupación de los artesanos blancos fue impedir a miembros de otras etnias de la sociedad el ejercicio de sus oficios. ${ }^{143}$ Por ello, a mediados del siglo XVI, prácticamente todos los talleres y tiendas de artesanos en Indias laboraban maestros españoles o sus descendientes criollos, mientras otras etnias como indios y negros solo fueron admitidos en calidad de auxiliares del trabajo manual más pesado, pero se les impidió ser oficiales y aprendices que con el transcurrir del tiempo podrían ser maestros. ${ }^{144}$ A diferencia de México y otras grandes ciudades, en Mérida la inexistencia de esas corporaciones y de sus rígidas normas permitió el proceso de transferencia de la jerarquía artesanal desde el predominio absoluto de los blancos hasta la substancial participación de otras etnias, desde la segunda mitad del siglo XVI y se acentuó en el siglo XVIII, como lo revelan las fuentes consultadas.

142 En 1618, Santiago de Ybatao se hizo cargo de un peso de plata por el requinto de forasteros de Santiago indio sillero del Perú. AGEM, Protocolos t.v, Carta de pago de requinto. Mérida, 24 de septiembre de 1618, ff.361r.-v. En 1666, Jacinto Martínez de Villalva, juez de las reales cobranzas, se hizo cargo del pago de requinto de forasteros de Cristóbal de Salinas, indio oficial de sastre, procedente de Muzo. AGNB, Real Hacienda, Cuentas t.396c- y 452c. Cajas Reales. Anexo al Cuaderno del Cargo de Jacinto Martínez de Villalva, Requintos de forasteros. Mérida, 2 de junio de 1666, f.12r. Lo obligación de pagar el requinto de forasteros ameritó la prestación de fianzas en 1638, Juan Cordero de Trejo, y Joseph Hernández, prestaron fianza a favor de Baltasar de los Reyes mulato oficial de sillero por 22 patacones que debía del requinto de forasteros. AGEM, Protocolos t.xv, Carta de fianza. Mérida, 19 de octubre de 1638, f. 88r-v.

143 M. Pérez Vila, “El artesanado la formación de una clase media”, pp.329-331.

144 J. González Angulo, Los gremios de artesanos y el régimen de castas. 
En la Nueva Granada, la presencia de numerosa población indígena que fue sometida al régimen de encomienda determinó que la mano de obra empleada para diversas labores fuera fundamentalmente aborigen, los peninsulares obligaron a los naturales a efectuar los trabajos como la construcción de las ciudades, la siembra y recolección de alimentos, la conformación de haciendas y otros núcleos de producción agrícolas y pecuarios, al mismo tiempo que les imponían labores del hilado y tejido de algodón y otras fibras textiles, que como en el caso de Mérida corría por moneda. De esa forma el componente indígena fue obteniendo la enseñanza y la destreza necesaria para efectuar el trabajo artesanal en los diversos oficios, por eso no extraña que la mayoría de los artesanos que expresan su grupo étnico sean indios con un $18 \%$ (véase gráfico 4).

\section{GRAFICO 4 \\ DISTRIBUCION ETNICA DE LOS ARTESANO EN MERIDA. 1558-1700}

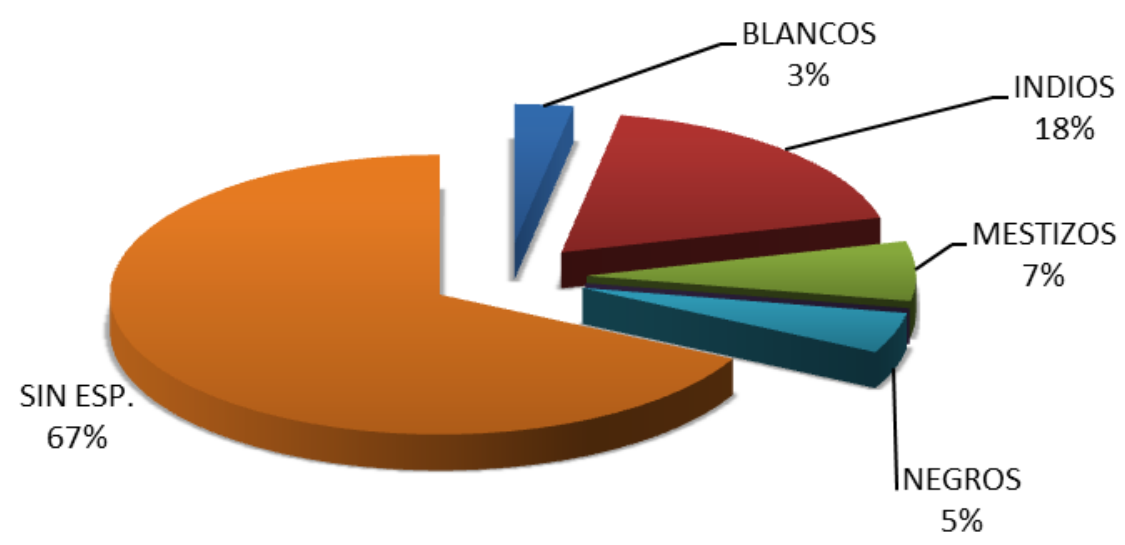

Fuente: AGEM, Protocolos ts. I-XL y Mortuorias t.I-X.

Del mismo modo, la creciente población mestiza que surge después del contacto indohispánico, la que estaba relevada de pagar tributo pero que se desenvolvía entre dos sectores étnicos también desempeñó labores artesanales que en la ciudad de los picos nevados asciende a un 7\% (véase gráfico 4). En el caso de los blancos, los que poseían los conocimientos y destrezas para realizar el trabajo artesanal, se dedicaron al mismo en las décadas inmediatas a la fundación de Mérida y hasta finales del siglo XVII, pero una vez cumplido el ciclo de transferencia y enseñanza de los oficios se desligan de las mismas y asumen otras actividades de mayor 
rango en la sociedad colonial emeritense, por esas razones su índice es sumamente reducido con sólo un $3 \%$ (véase gráfico 4 ).

Finalmente están los negros, cuyo trabajo se desarrolló fundamentalmente como auxiliares del proceso productivo de las haciendas y estancias en la producción de herramientas como rejas calzaduras, clavos, machetes, azuelas, tasíses y otros, por eso sus amos los asientan para que aprendan las labores de la herrería y como surradores y talabarteros y ocasionalmente el de sastres y representan sólo el $5 \%$ de la población artesana. En los primeros siglos del periodo colonial, los esclavos negros fueron una mano de obra minoritaria en el ejercicio del trabajo artesanal, pero se considera que al avanzar aquella época, los esclavos artesanos hicieron más significativa su presencia en el desempeño de esta actividad. Sin embargo, es preciso acotar que la documentación estudiada para Mérida proporciona una reducida información sobre el grupo étnico al cual pertenecieron los artesanos, puesto que alrededor del $63.5 \%$ no explicita su etnia (véase gráfico 4).

\section{Conclusiones}

El régimen de trabajo al que estuvieron adscritos los artesanos emeritenses durante los siglos XVI y XVII, estuvo íntimamente vinculado con los sistemas laborales que introdujeron los peninsulares en América. Ciertamente, la encomienda, el concierto artesanal en sus dos modalidades de obra y servicio, el asiento de aprendizaje y la esclavitud fueron los marcos en los cuales se desarrollo el trabajo y la producción artesanal, con sus particularidades, pero en todos se mantuvo las formas de coerción legal, extralegal, económica y familiar para la realización de las labores. Aunque en el concierto artesanal los individuos gozaron de cierta libertad para escoger sus oficios, patrones, clientes y condiciones de trabajo, estuvieron relegados por su condición étnica, aunque en Mérida la ausencia de gremios y corporaciones permitió la participación en todos los oficios de los diversos grupos étnicos. En el concierto de servicio artesanal los trabajadores tuvieron la posibilidad de devengar el salario que fue cancelado en metálico o mixto discriminado en metálico y especies.

Por otra parte, los asientos de aprendizaje, el que fue un sistema laboral se proporcionó capacitación a los aprendices, quienes en ocasiones, fueron huérfanos, hijos de viudas pobres o criados en casas de los vecinos de la ciudad, mediante el cual les permitió obtener calificación necesaria para desempeñar con éxito una la- 
bor y alcanzar a través de su trabajo una remuneración y ascender en la jerarquía artesanal, mediante el cumplimiento de ciertos requisitos, lo que también en la mayoría de los casos le permitía obtener cierta libertad laboral, económica y social. Asimismo, significó una forma notable de proporcionar mano de obra calificada al mercado laboral de la ciudad, producir, fabricar las obras de infraestructura, enseres, ropa, utensilios y otros requeridos por los vecinos de la misma.

Por el contrario en los regímenes de la encomienda y la esclavitud el trabajo artesanal fue compulsivo y mediante estos sistemas se obligó a indígenas y afrodescendientes al aprendizaje y realización de labores artesanales por las que no recibieron contraprestación sino que debieron ser cedidas a los encomenderos en pago de sus tributos y a los esclavistas como propietarios del trabajo de los siervos.

\section{Bibliografía:}

\section{Fuentes primarias:}

Archivo Arquidiocesano de Mérida (AAM) (Mérida-Venezuela).

Seminario Caja 1 Inventario de los papeles del Colegio de San Francisco Xavier de la Compañía de Jesús, 1775.

Archivo General del Estado Mérida (AGEM) (Mérida-Venezuela): Protocolos tomos I a XL; Mortuorias tomos I a X.

Archivo General de la Nación (AGNC) (Bogotá- Colombia), fondos: Visitas de Venezuela; Real Hacienda. Cuentas, Cajas Reales de Mérida.

Archivo General de Indias (AGI) (Sevilla-España): Santa Fe; Indiferente General

\section{Documentales publicadas}

Probanza de Juan Rodríguez Xuárez, Mérida, Consejo Municipal de Libertador 425 años de la Historia de Mérida, 1983.

Recopilación de Leyes de Indias 1681, Madrid, Cultura Hispánica, 1973.

"Relación Geográfica hecha por Diego de Villanueva y Gibaja de la Gobernación de Venezuela, Los Corregimientos de La Grita y Tunja y la Gobernación de los Mussos año 
de 1607”, en Antonio Arellano (comp.), Relaciones geográficas de Venezuela. Caracas, Academia Nacional de la Historia, 1964,. pp.285-302.

Testimonios para la formación del trabajo, Caracas, Instituto Nacional de Cooperación Educativa, 1972.

\section{Historiografía:}

Acosta Saignes, Miguel, Vida de los esclavos negros en Venezuela, Caracas, Ed. Hespérides, 1970.

Aguado, Pedro de, Recopilación historial de Venezuela, t.II, Caracas, Academia Nacional de la Historia, 1963.

Alemparte, Julio, "La regulación económica en Chile durante la colonia II", en Anales de la Facultad de Ciencias Jurídicas y Sociales vol.2, n. ${ }^{\circ}$, Santiago de Chile, Universidad de Chile, 1936.

Álvarez, Rafael, “Artesanos y producción manufacturera en la Nueva Granada, la industria textil en la Provincia del Socorro, siglos XVIII y XIX”, en Revista Procesos Históricos n. ${ }^{\circ}$ 10, Mérida, Universidad de los Andes, 2010, pp.1-40.

Arcila Farías, Eduardo, El régimen de la encomienda en Venezuela, Caracas, Universidad Central de Venezuela, 1967.

Arellano Moreno, Antonio (comp.), Relaciones geográficas de Venezuela, Caracas Academia Nacional de la Historia, 1964.

Bird Simpson, Lesley, Los conquistadores y el indio americano, Barcelona, Eds. Península, 1970.

Brines Tyrer, Robson, The demographic and Economic History of the Audiencia de Quito and the Textile Industry 1600-180o, Ph. Discuss, University of California at Berkeley, 1976.

Brito Figueroa, Federico, El problema tierra y esclavos en la Historia de Venezuela, Caracas, Asamblea Legislativa del Estado Aragua, 1973.

Brito Figueroa Federico, Historia económica y social de Venezuela, Caracas, Universidad Central de Venezuela, 1975.

Browser, Frederick P., El esclavo africano en el Perú colonial (1524-1650), México, Siglo XXI Eds., 1977.

Carmagnani, Marcelo, El salario minero en Chile colonial, Santiago de Chile, Universidad de Santiago de Chile, 1963. 
Caro Baroja, Julio, Inquisición brujería y criptojudaismo, Barcelona, Ariel, 1974.

Castillo Matheiu, Nicolás del, Esclavos negros en Cartagena y sus aportes léxicos, Bogotá, Instituto Caro y Cuervo, 1982.

Céspedes del Castillo, Guillermo, "La visita como Institución Indiana” en, Anuario de Estudios Americanos Sevilla, t.III, Sevilla, EEHA, 1943.

Colmenares, Germán, Historia económica y social de Colombia 1537-1719, Bogotá, Ed. la Carreta, 1978.

Colmenares, Germán, Historia económica y social de Colombia II. Popayán una sociedad esclavista. 1680-180o, Bogotá. Ed. La Carreta, 1979.

Duarte, Carlos F., Muebles venezolanos. Siglos XVI, XVII y XVII, Caracas, Grupo Cuatro Editor, 1966.

Duarte, Carlos F., "Historia y origen de varias obras atribuidas a Juan Pedro López”, en Separata del Boletín Histórico n. ${ }^{\circ}$ 30, Caracas, Fundación John Boulton, 1972.

Duarte, Carlos F., "El autor de la custodia preciosa de la catedral de Caracas", en Separata del Boletín Histórico n. ${ }^{\circ}$ 33, Caracas, Fundación John Boulton, 1973.

Duarte, Carlos F., "Un portapaz del siglo XVI en la catedral de Caracas”, en Separata del Boletín Histórico n. ${ }^{\circ}$ 41, Caracas, Fundación John Boulton, 1976.

Duarte, Carlos F., "Loza hecha en Venezuela durante la dominación española”, en Separata del Boletín Histórico n. ${ }^{\circ}$ 44, Caracas, Fundación John Boulton, 1977.

Duarte, Carlos F., Los maestros fundidores en el período colonial en Venezuela, Caracas, Monte Ávila Eds., 1978.

Duarte, Carlos F., Historia de la alfombra en Venezuela, Caracas, Ed. Arte, 1979.

Duque Castro, María, "Nuevos ciudadanos entre el imperio español y la república colombiana” en Boletín Americanista vol.LX, n. ${ }^{\circ} 60$, Barcelona, Universidad de Barcelona, 2010, pp.165-186.

Farfán, Hilda, "La artesanía en la provincia de Venezuela su importancia económica y social (1750-1850)", en Faces vol.6, n. ${ }^{\circ}$ 12, Carabobo, Universidad de Carabobo, 1996, pp.108-133.

Febres Cordero, Tulio, "Sobre el criollismo artes e industrias que fueron", en Tulio Febres Cordero, Mitos y tradiciones, Mérida, Universidad de los Andes, 1983, pp.169-170.

Gamboa, Jorge, "La encomienda y las sociedades indígenas en el Nuevo Reino de Granada. El caso de la provincia de Pamplona1549-1650", en Revista de Indias vol.LXIV, n. ${ }^{\circ} 23$, Sevilla, EEHA/CSIC, pp.749-770. 
García Zambrano, Ángel, El remodelado interior de la catedral de Puebla, Mérida, Universidad de Los Andes, 1984.

García Zambrano, Ángel, "La Iglesia Mayor de Mérida”, en Boletín de la Academia Nacional de la Historia vol.LXIX, n. ${ }^{\circ} 276$, Caracas, Academia Nacional de la Historia, 1985, pp.1079-1096.

González, Margarita, "Bosquejo histórico de las formas del trabajo indígena”, en Margarita González, Ensayos de historia Colombiana, Medellín, Ed. La Carreta, 1974, pp.963.

González Angulo, Jorge, "Los gremios de artesanos y el régimen de castas", en Sonia Lombardo et al, (eds.), Organización de la producción y relaciones de trabajo en el siglo XIX en México, México, INAH, 1979, pp.148-159.

Ghosh, Santosh K., Algunos Testimonios de la Arquitectura Colonial Merideña, Mérida, Museo de Arte Colonial y Facultad de Humanidades y Educación, 1981.

Gutiérrez Azopardo, Ildefonso, Historia del negro en Colombia ¿̇umisión o rebeldía?, Bogotá, Nueva América, 1980.

Herrera, Gina, Participación, presencia y prácticas de los artesanos afrocoloniales en Cartagena de Indias (1770 - 1810). Bogotá, Universidad Javeriana, 2009.

Jara, Álvaro, “Importación de trabajadores indígenas en el siglo XVII”, en Revista Chilena de Historia y Geografía n. ${ }^{\circ} 124$, Santiago de Chile, 1958, pp.192-207.

Jara, Álvaro, "Fuentes para la Historia del Trabajo en el Reino de Chile III. Alquileres y ventas de Indios 1599-1620”, en Apartado de la Academia Chilena de la Historia n. ${ }^{\circ} 58$, Santiago de Chile, 1958, pp.102-135.

Jiménez, Francisco, "Implantación de la Encomienda en la Provincia de Tabasco", en Anuario de Estudios Americanos vol.LVII, n. ${ }^{\circ}$, Sevilla, EEHA, 2000, pp.13-38.

Kamen, Henry, La inquisición española, Madrid, Alianza Ed., 1974.

Khale, Guther, "La encomienda como institución militar en la América hispánica colonial”, en Anuario Colombiano de Historia Social y de la Cultura n. ${ }^{\circ} 9$, Bogotá, Universidad Nacional, 1979, pp.5-16.

Konetzke, Richard, América Latina la época colonial II, México, Ed. Siglo XXI, 1977.

La Marca Erazo, Rosa y Lobo, Ciria, El concierto en Mérida 1623-169o, Mérida, (tesis) Universidad de Los Andes, 1981.

Lombardi, John, Decadencia y abolición de la esclavitud en Venezuela. 1820-1854, Caracas, Universidad Central de Venezuela, 1974. 
Mantilla, Antonio, El régimen de la encomienda en Mérida, Mérida, (tesis) Universidad de Los Andes, 1979.

Manix, Daniel y Cowley, M., Historia de la trata de negros, Madrid, Alianza Ed., 1970.

Navarrete, María C., Génesis y desarrollo de la esclavitud en Colombia Siglos XVI y XVII, Cali, Universidad del Valle, 2005.

Navarrete, María C., "Los artesanos negros en la sociedad cartagenera del siglo XVII", en Historia y Espacio n. ${ }^{\circ} 15$, Cali, Universidad del Valle, 1994.

Ortiz de la Tabla, Xavier, "El obraje colonial ecuatoriano. Aproximación a su estudio", en Revista de Indias n. ${ }^{\circ}$ 149-150, Sevilla, EEHA/CSIC, 1977, pp.471-541.

Ots Capdequí, José María, Historia del Derecho español en América y del Derecho Indiano, Madrid, Aguilar, 1968.

Ots Capdequí, José María, El Estado español en las indias, México, Fondo de Cultura Económica, 1975.

Palacios Preciado, Jorge, La trata de negros por Cartagena de Indias, Tunja, Universidad Pedagógica y Tecnológica de Colombia, 1973.

Palacios Preciado, Jorge, Cartagena de Indias, gran factoría de la mano de obra esclava, Tunja, Eds. Pato Mariño, 1975.

Payne Iglesias, Elizet, "Maestros, oficiales y aprendices. La incipiente organización artesanal en la Cartago del siglo XVII", en Diálogos vol.1, n. ${ }^{\circ}$, San José de Costa Rica, Universidad de Costa Rica, 2000.

Pérez Vila, Manuel, "El artesanado, la formación de una clase media americana (15001800)", en Boletín de la Academia Nacional de la Historia vol.LXIX, n. ${ }^{\circ}{ }_{274}$, Caracas, Academia Nacional de la Historia, 1986, pp.327-341.

Picón Parra, Roberto, Fundadores, primeros moradores y familias coloniales de Mérida, ts.I-II, Caracas, Academia Nacional de la Historia, 1988.

Pla, Josefina, "Los talleres misioneros, su organización y funcionamiento", en Revista de Historia Argentina n. ${ }^{\circ}$ 75-76, Buenos Aires, 1973, pp.35-41.

Ramírez, Luis Alberto, La mano de obra artesana en Mérida 1623-1678. Ponencia presentada ante XXX Convención Anual de ASOVAC, Mérida, 1980.

Ramírez, Luis Alberto, La artesanía colonial de Mérida 1623-1678, Mérida, (tesis) Universidad de Los Andes, 1980. 
Ramírez, Luis Alberto, “Tradición, familia y parentesco en el artesanado merideño de los siglos XVI y XVII", en Revista Montalbán n. ${ }^{\circ}$ 29, Caracas, Universidad Católica andrés Bello, 1996, pp.197-215.

Ramírez, Luis Alberto, La artesanía colonial en Mérida (1558-170o), Caracas, Academia Nacional de la Historia, 2007.

Ramírez, Luis Alberto, La tierra prometida del sur del lago de Maracaibo y la villa y puerto de San Antonio de Gibraltar, t.I, Caracas, Ed. el Perro y la Rana, 2011.

Ramírez, Luis Alberto, "Los maestros artesanos en Mérida (siglos XVI-XVII)", en Presente y Pasado vol.18, n. ${ }^{\circ}$ 36, Mérida, Universidad de los Andes, 2013, pp.28-52.

Recopilación de Leyes de Indias 1681, t.II, Madrid, Cultura Hispánica, 1973.

Rivas Belandria, J.J., Antecedentes coloniales de nuestra legislación laboral, Mérida, Universidad de Los Andes, 1965.

Rojas, Reinaldo, El régimen de la encomienda en Barquisimeto colonial, Caracas, Academia Nacional de la Historia, 1992.

Salas de Coloma, Miriam, De los obrajes de Canaria y Chincheros a las comunidades indígenas de Vilcashuamán. Siglo XVI, Lima, Ed. Sesator, 1963.

Samudio, Edda, "La enseñanza de los oficios artesanales en Mérida", en El trabajo y los trabajadores en Mérida colonial. Fuentes para su estudio, San Cristóbal, Universidad Católica del Táchira, 1988, pp.267-312.

Samudio, Edda, Seventeenth Century Migration in the Venezuela Andes, Edited by David Robinson Cambridge Studies in Historical Geography, 1990.

Samudio, Edda, "El concierto agrario", en El trabajo y los trabajadores en Mérida Colonial. Fuentes para su Estudio, San Cristóbal, Universidad Católica del Táchira, 1988.

Samudio, Edda, "Los esclavos de las haciendas del colegio San Francisco Xavier de Mérida”, en Separata de la revista Paramillo n. ${ }^{\circ} 17$, San Cristóbal, Universidad Católica del Táchira, 1998, p.432.

Samudio, Edda, "La tasa para los indios de Mérida de 1593", en II Jornadas de Investigación Histórica, Caracas, Universidad Central de Venezuela, 1992.

Santiago Lobo, Zoraida, Aspectos socioeconómicos de los esclavos negros en Mérida 1788180o, Mérida, (tesis) Universidad de Los Andes, 1982. 
Sharp, William, "La rentabilidad de la esclavitud en el Chocó 1610-1810", en Anuario Colombiano de Historia Social y de la Cultura n. ${ }^{\circ}$, Bogotá, Universidad Nacional, 1987, pp.19-45.

Silva Santisteban, Fernando, Los obrajes en el virreinato del Perú, Lima, Museo Nacional de Historia, 1964.

Solano, Sergio Paolo, "Sistema de defensa, artesanado y sociedad en el Nuevo Reino de Granada. El caso de Cartagena de Indias. 1750-1810”, en Memorias, vol.10, n. ${ }^{\circ} 19$, Barranquilla, Universidad del Norte, 2013, pp.2-139.

Tardieu, Jean Pierre, "Negros e indios en el obraje de San Ildefonso. Real Audiencia de Quito 1665-1666", en Revista de Indias vol.LXXII, n. ${ }^{\circ}$ 255, Sevilla, EEHA/CSIC, 2012, pp.527-550.

Testimonios para la formación del trabajo, Caracas, Instituto Nacional de Cooperación Educativa, 1972.

Troconis de Veracoechea, Ermila, Documentos para el estudio de los esclavos negros en Venezuela, Caracas, Academia Nacional de la Historia, 1969.

Valencia Villa, Carlos, Alma en boca y huesos en costal. Una aproximación a los contrastes socio-económicos de la esclavitud, Santa Fe, Mariquita y Mompox, Bogotá, ICANH, 2003.

Vilar, Pierre, Iniciación al vocabulario histórico, Barcelona, Grijalbo, 1980. 